\title{
Cooperation preferences and framing effects
}

\author{
Citation for published version (APA):
}

Petit Dit Dariel, A. C. (2013). Cooperation preferences and framing effects. Maastricht University, Graduate School of Business and Economics. GSBE Research Memoranda No. 010 https://doi.org/10.26481/umagsb.2013010

Document status and date:

Published: 01/01/2013

DOI:

10.26481/umagsb.2013010

Document Version:

Publisher's PDF, also known as Version of record

\section{Please check the document version of this publication:}

- A submitted manuscript is the version of the article upon submission and before peer-review. There can be important differences between the submitted version and the official published version of record.

People interested in the research are advised to contact the author for the final version of the publication, or visit the DOI to the publisher's website.

- The final author version and the galley proof are versions of the publication after peer review.

- The final published version features the final layout of the paper including the volume, issue and page numbers.

Link to publication

\footnotetext{
General rights rights.

- You may freely distribute the URL identifying the publication in the public portal. please follow below link for the End User Agreement:

www.umlib.nl/taverne-license

Take down policy

If you believe that this document breaches copyright please contact us at:

repository@maastrichtuniversity.nl

providing details and we will investigate your claim.
}

Copyright and moral rights for the publications made accessible in the public portal are retained by the authors and/or other copyright owners and it is a condition of accessing publications that users recognise and abide by the legal requirements associated with these

- Users may download and print one copy of any publication from the public portal for the purpose of private study or research.

- You may not further distribute the material or use it for any profit-making activity or commercial gain

If the publication is distributed under the terms of Article $25 \mathrm{fa}$ of the Dutch Copyright Act, indicated by the "Taverne" license above, 


\section{Maastricht University}

Aurélie Dariel

Cooperation preferences and framing effects

$\mathrm{RM} / 13 / 010$

\section{GSBE}

Maastricht University School of Business and Economics

Graduate School of Business and Economics

P.O Box 616

NL- 6200 MD Maastricht

The Netherlands 


\title{
Cooperation preferences and framing effects*
}

\author{
Aurélie Dariel ${ }^{\dagger}$
}

February 12, 2013

\begin{abstract}
This paper presents the results from an experiment investigating whether framing affects the elicitation and predictive power of preferences for cooperation, i.e., the willingness to cooperate with others. Cooperation preferences are elicited in three treatments using the method of Fischbacher, Gächter and Fehr (2001). The treatments vary two features of their method: the sequence and order in which the contributions of other group members are presented. The predictive power of the elicited preferences is evaluated in a one-shot and a finitely-repeated public-good game. I find that the order in which the contributions of others are presented, by and large, has no impact on the elicited preferences and their predictive power. In contrast, presenting the contributions of others in a sequence has a pronounced effect on the elicited preferences and reduces substantially their predictive power. Overall, elicited preferences are more accurate at predicting behavior when others' contributions are presented simultaneously and in ascending order, like in Fischbacher, Gächter and Fehr (2001).
\end{abstract}

JEL codes: C91, H41

Keywords: public-good game, strategy method, predictive power, framing effect

${ }^{*}$ This paper is based on the third chapter of my dissertation. I am grateful to Nikos Nikiforakis and Arno Riedl for useful comments. The research in this paper was supported by the Swiss National Fund (SNF) under grant 100014-126954. The paper was partly written while I was visiting the University of Grenoble.

${ }^{\dagger}$ Department of Economics, University of Bern and Department of Economics, Maastricht University; email: aurelie.dariel@vwi.unibe.ch 


\section{Introduction}

This paper presents the results from a laboratory experiment investigating the sensitivity of cooperation preferences to framing effects. Cooperation preferences can be defined as the willingness to cooperate with others when private and group interest are at odds (Fischbacher and Gächter, 2010). Evidence from laboratory experiments indicates that, while some people are unwilling to cooperate with others, many individuals are willing to cooperate provided that others in their group do the same (e.g., Fischbacher, Gächter and Fehr, 2001; Kocher et al., 2008; Rustagi, Engel and Kosfeld, 2010; Thöni, Tyran and Wengström, 2012). At the same time, there is also evidence that framing affects cooperation in public-good games and other social dilemmas. Despite this, it remains unknown whether cooperation preferences are sensitive to framing effects.

A framing effect is said to occur when seemingly superficial changes in the presentation of a task affect behavior without affecting material incentives. For example, Andreoni (1995) finds that contributions in a public-good game are considerably lower when the experimental instructions emphasize the negative externality imposed to others by not contributing to the public good, than when they highlight the positive externality generated by contributions. Similarly, individuals are more likely to cooperate with others when the prisoner's dilemma is called the "Community Game" than when it is called the "Wall Street Game" (Kay and Ross, 2003; Liberman et al., 2004; Ross and Ward, 1996) or the "Stock Market Game" (Ellingsen et al., 2012). ${ }^{1}$

Recent studies have argued that framing affects cooperation not by changing preferences, but by changing beliefs about the actions of others (Dufwenberg et al. 2011; Ellingsen et al., 2012; Nikiforakis, 2010). However, none of the aforementioned studies has elicited individuals' preferences for cooperation. Framing has been known to affect choices in non-strategic environments where beliefs about the actions of others should play no role, such as when choosing a lottery (e.g., Kahneman \& Tversky, 1986). Therefore, it remains an open question whether cooperation preferences are unaffected by framing.

To elicit cooperation preferences in the present experiment I use the method of Fischbacher, Gächter and Fehr (2001; henceforth, FGF). This method has been used in a number of studies, including Fischbacher and Gächter (2010) who showed that the elicited preferences for cooperation are positively correlated with contributions in a finitely-repeated public-good game. ${ }^{2}$ Participants

\footnotetext{
${ }^{1}$ Other studies that find framing effects in social dilemmas are Bougherara, Denant-Boemont, Masclet (2011), Brandts and Schwieren (2009), Brewer and Kramer (1986), Cookson (2000), Cubitt et al., (2011), Fosgaard, Garn Hansen and Wengström (2011), Kotani, Managi, Tanaka (2008), McCusker and Carnevale (1995), McDaniel and Sistrunk (1991), Nikiforakis (2010), Park (2000), Rege and Telle (2004), Sell and Son (1997), Sonnemans et al. (1998), van Dijk and Wilke (2000), and Willinger and Zielgelmeyer (1999).

${ }^{2}$ For other studies using this method see Burlando and Guala (2005), Cheung (2012), Herrmann and Thöni (2009), Kocher et al., (2008), Muller, Sefton, Steinberg, Vesterlund (2008), Rustagi, Engel and Kosfeld (2010),
} 
in the experiment are asked in an incentive-compatible way to state how much they are willing to contribute to a public account given the average contribution of the others' group members. The elicited contribution schedules reflect a subject's cooperation preferences. The findings indicate that the majority of participants provides monotonic and increasing contribution schedules. That is, they are willing to contribute more as the average contribution of others increases.

In the present study, framing takes the form of altering the way in which the strategy method is administered. Two features of the FGF method, as it has been used so far, are that the possible contributions of others are presented $(i)$ simultaneously in a table, and $(i i)$ in an order (i.e., 0, $1,2, \ldots$ 20). These features, however, could affect the elicited preferences for cooperation. For example, the ordering of others' contributions could serve as a cue for subjects to condition their contribution on that of others. Similarly, the simultaneous frame in the strategy method may place subjects in a "cold" state when making their decisions (e.g., Brandts and Charness, 2000; Brosig, Weimann and Yang, 2003; Gueth, Huck, and Mueller, 2001), while the sequential frame may place them in a state that is more similar to that in the standard public-good game. At the same time, however, ordering and sequentiality could affect the level of noise in the elicitation of cooperation preferences and affect its predictive power. ${ }^{3}$

The experiment consists of three parts. In the first part, I elicit subjects' cooperation preferences using the FGF method under three different frames. In the CONTROL treatment, all possible contributions of others are presented simultaneously in a table, but, unlike FGF, in a random order. In the second treatment (ORDERED), as in FGF, the possible contributions of others are presented simultaneously and in an ascending order. In the third treatment (SEQUENTIAL), the possible contributions of the other group members are presented in the same random order as in the CONTROL treatment, but sequentially, one by one. In the second and third part of the experiment, I evaluate the predictive power of the elicited cooperation preferences in a one-shot and a finitely-repeated public-good game in which subjects are rematched in every period.

In a recent article, Levy-Garboua, Maafi, Masclet and Terracol (2012) elicit subjects' risk preferences using the Holt and Laury (2002) method under a variety of frames and find that both the ordering of options as well as whether choices are made simultaneously or sequentially affect the consistency of choices and the extent of risk aversion. ${ }^{4}$ These findings suggest that the

Thöni, Tyran and Wengström (2009), and Volk, Thöni and Ruigrok (2012).

${ }^{3}$ For example, Fischbacher and Gächter (2010) classify 10 percent of their subjects as "confused" if they could not be classified as either selfish, conditionally cooperative or triangular. The authors report that contributions in the finitely-repeated game of confused subjects were not well predicted by their contribution schedules.

${ }^{4} \mathrm{~A}$ subject is said to be inconsistent in Levy-Garboua et al. (2012) when their preferences cannot be explained with a standard utility function. The authors find that the rate of inconsistent choices and the level of risk aversion are higher when choices are made sequentially, and when choices are not orderred. Levy-Garboua et al. (2012) do not test the predictive power of the elicited risk preferences. 
number of participants with non-monotonic elicited cooperation preferences may be higher in the SEQUENTIAL relative to the CONTROL treatment but lower in the ORDERED compared to the CONTROL treatment. ${ }^{5}$. However, it is unclear under which condition the elicited preferences will be better predictors of actual contributions in the public-good game. For example, although the extent of noise may be greater in the SEQUENTIAL relative to the CONTROL treatment, contribution schedules may still be better predictors of behavior, if the sequential frame places individuals in a similar (hot) state as in the one-shot and finitely-repeated game.

The experimental results indicate that this is not the case. The predictive power of the contribution schedules is higher in CONTROL than in SEQUENTIAL, both in the one-shot and in the finitely-repeated game. This is partly due to the high number of individuals providing nonmonotonic contribution schedules (90 percent of all subjects in this treatment). In contrast, the ordering of others' contributions, by and large, does not affect the predictive power of the elicited schedules. This is the case, despite the fact that, similar to Levy-Garboua et al. (2012), the rate of participants' with non-monotonic contribution schedules is higher in CONTROL (50 percent) than in ORDERED (30 percent). In general, the frames affect neither contributions nor beliefs in the first two parts of the experiment, but some differences are observed in the third part in SEQUENTIAL. I conclude that the simultaneous presentation of others' contributions in an order are appealing features of the FGF method.

The paper proceeds as follows. In the next section, I present the experimental design in detail. In section 3, I discuss the experimental results, while section 4 concludes.

\section{The experiment}

The experiment consists of three parts. The existence of the three parts is public knowledge, but participants are not informed about the content of each part in advance. In the first part, I elicit participants' contribution schedules using variants of the FGF strategy method. In the second part, participants play a one-shot public-good game, and in the third part, they play a finitely-repeated version of the game. The experiment consists of three treatments. The treatment manipulation occurs only in the first part of the experiment. The second and third part are identical across treatments.

This section begins by presenting the basic public-good game. This is followed by a detailed presentation of each of the three parts and the experimental treatments. The section concludes with a discussion of the experimental procedures.

\footnotetext{
${ }^{5}$ As I discuss later in the paper, non-monotonic contribution schedules cannot be explained by most standard models used to explain behavior in social dilemmas.
} 


\subsection{The public-good game}

Participants are randomly divided into groups of three players. Each group member is given an endowment of 20 tokens and has to decide how to divide them between a private and a public account. The payoff function for each group member $i$ is:

$$
\pi_{i}=20-g_{i}+0.5 \sum_{j=1}^{3} g_{j},
$$

where $g_{i} \in\{0,1, \ldots 20\}$ is the contribution of individual $i$ to the public account. The marginal return of the public account is 0.5 , i.e., contributing 1 token to the public account yields a private return of 0.5. Therefore, if an individual wishes to maximize his/her material payoff, s/he should not contribute to the public account. However, since there are three individuals in the group, each token contributed to the public account increases group earnings by 1.5. Therefore, there is a tension between private and group interest.

In the one-shot public-good game, individuals wishing to maximize their material payoff have a dominant strategy to contribute zero to the public account. However, as mentioned, this prediction fails to account for the fact that many subjects contribute positive amounts to the public account, and the fact that many of them are classified as "conditional cooperators", i.e. individuals who contribute if they believe others do so. Fehr and Schmidt (1999, Proposition IV) show that if some group members dislike inequality in material payoffs sufficiently, then positive contributions can be sustained in equilibrium in the public-good game. The authors also show that the contribution of inequality-averse individuals will increase monotonically with the average contribution of other players in their group. Therefore, the model of Fehr and Schmidt (1999) provides an explanation for conditional cooperation in public-good experiments. ${ }^{6}$ The intuition is that the inequalityaverse individuals will suffer from the inequality when contributing less than the others. Similar predictions are obtained using the model of Bolton and Ockenfels (2000).

\subsection{Eliciting contribution schedules and beliefs}

In the first part of the experiment, I employ the method of Fischbacher, Gächter, Fehr (2001) for eliciting contribution schedules in the public-good game. Participants are randomly matched to form an anonymous group of three players and told that they will have to make three kinds of decisions. First, they have to decide on an unconditional contribution to the public account.

\footnotetext{
${ }^{6}$ Note that the Fehr-Schmidt model cannot readily explain conditional cooperation in the experiment of FGF (or the one in this paper) as subjects are allowed to condition their behavior only on the average contribution of their peers and not on the existence or the extent of inequality in earnings.
} 
Second, they have to decide how much they are willing to contribute for each possible (rounded) average contribution of the other two members of his group $(0,1, \ldots 20)$. I will refer to this set of 21 decisions as the contribution schedule. Third, participants have to estimate the (rounded) average unconditional contribution of the other two group members.

The three treatments differ only with regards to the way in which the contribution schedule is elicited. In the CONTROL treatment, the possible contributions of the other group members are presented simultaneously, i.e, in a contribution table, but in a random order. ${ }^{7}$ In the ORDERED treatment, all possible contributions by the other group members are presented simultaneously in a table, in an ascending order. That is, the ORDERED treatment replicates the design of FGF. In the SEQUENTIAL treatment, the ordering of others' contributions was the same as in the CONTROL treatment, but others' contributions were presented sequentially, in 21 successive screens.

All decisions are incentive compatible. In particular, after all participants made their decisions, two subjects in each group were randomly selected and their unconditional contribution was the one relevant for determining their contribution to the public account. For the third subject, the contribution schedule determined their contribution to the public account. In particular, their contribution was chosen based on their contribution schedule and the average unconditional contribution of the other two group members. To incentivize participants to thruthfully reveal their beliefs, they are told that they will receive 3 tokens for stating a belief that exactly matches the average contribution of the other two group members. If their belief is within $+/-1$ of the average, they will receive 2 tokens. If their estimate is within $+/-2$ of the average they will receive 1 token. Otherwise, they will not receive any additional tokens.

\subsection{The one-shot public-good game}

In the second part of the experiment, participants are informed that they will be placed in a new group and that they will play a one-shot public-good game. The one-shot game allows to analyze players' individual responses in a one-shot interaction without repetition effect and learning.

In order to evaluate the predictive power of the individuals' contribution schedule, I also elicite their beliefs about the average contribution of the other group members. Furthermore, to avoid choices in the strategy method affecting decisions in the one-shot game, participants do not receive feedback about the outcomes of the first part of the experiment.

\footnotetext{
${ }^{7}$ The order was determined by placing 21 numbered pieces of paper in a basket and picking them out sequentially and without replacement before the start of the first experimental session. The order was kept constant in subsequent sessions.
} 


\subsection{The finitely-repeated public-good game}

At the start of the third and final part of the experiment, participants are informed that they will play the public-good game for ten periods and that the composition of their group would be randomly determined at the start of each period. I note that, following Fischbacher and Gächter (2010), before playing the finitely-repeated game, they are informed about their earnings from the first and second part of the experiment, and the average contributions of their fellow group members. In each period, participants have to decide how much to contribute to the public account and, in addition, provide an estimate of how much they believe the other two group members would contribute on average. Participants receive feedback similar to that in the one-shot game at the end of each period.

\subsection{Procedures}

The experiment was conducted at the University of Zurich using Z-tree (Fischbacher, 2007). Three sessions were run for each treatment with a total of 96 participants (30 in CONTROL, 33 in OR$D E R E D$, and 33 in SEQUENTIAL). Each subject participated only in one experimental treatment. At the beginning of each session participants were randomly allocated to a closed cubicle, where they could make their decisions in complete anonymity from the other participants. Sessions lasted on average 90 minutes and participants earned $46.17 \mathrm{CHF}$ on average. At the time of the experiment, the exchange rate between the Swiss Franc and the American Dollar was $1 \mathrm{CHF}=\$ 1.23$

The experimental instructions were adopted from FGF and given to subjects on paper. Instructions for Part 1 were handed out first. Participants were informed that there would be a second and third part to the experiment, but they had no prior knowledge of what the content of these parts would be. Instructions for the second part were not handed out until the end of first part, and similarly for the third part. In the instructions, the contribution table was presenting and explained in the CONTROL and ORDERED treatments. In the SEQUENTIAL treatment, two screens were presented to the participants and they did no know the sequence of others' contribution before playing the game.

After participants had read the instructions, they had to answer control questions which tested their understanding of the experiment. The experiment did not start until all participants had answered correctly the control questions. The procedures for the second and third part of the experiment were the same. At the end of the experiment the total amount of tokens earned by participants was converted to Swiss francs at the rate of 1 token $=0.6 \mathrm{CHF}$ for the strategy method and the one-shot game, and, since each individual made 10 decisions in the third part, at the rate of 1 token $=0.06 \mathrm{CHF}$ for the finitely-repeated game. 


\section{Results}

This section is divided into four parts. The first part examines the impact of the different frames on the contribution schedules and, in particular, whether it affects the rate of non-monotonic contribution schedules. The second part investigates the predictive power of the contribution schedules under the different frames in the one-shot public-good game, while the third part does the same for the finitely-repeated game. The fourth part discusses other experimental findings such as the impact of the different frames on the distribution of cooperation preferences and the levels of contribution in the one-shot and finitely-repeated games.

\subsection{Non-monotonic contribution schedules}

All studies using the FGF method for eliciting cooperation preferences find that a non-trivial fraction of individuals provides non-monotonic contribution schedules. As mentioned, there are reasons to expect that there may be more (less) non-monotonic contribution schedules in the SEQUENTIAL (ORDERED) treatment compared to the CONTROL treatment.

Let $G$ denote the average contribution of one's group members, $G \in\{0,1, \ldots 20\}$, and $g_{i}(G)$ the contribution of individual $i$ given the average contribution of his peers. A contribution schedule is weakly monotonic if $g_{i}(G+1) \geq g_{i}(G)$ for all $G \in[0,19]$, or $g_{i}(G+1) \leq g_{i}(G)$. A contribution schedule that does not satisfy either of these conditions is non-monotonic. For example, an individual who always contributes $g_{i}(G)=0$ has a weakly monotonic schedule. A perfect conditional cooperator contributes $g_{i}(G)=G$ and has a strictly monotonic schedule. An individual who contributes $g_{i}(0)=0, g_{i}(1)=2, g_{i}(2)=1$, and $g_{i}(3)=4$ has a non-monotonic schedule. To have a measure of how "noisy" these schedules are, I will sometimes refer to the number of switches in the non-monotonic schedule of an individual. For example, in the previous example, individual $i$ made one switch when he contributed $g_{i}(2)=1$ (since before that he had an increasing contribution schedule), and a second switch when he contributed $g_{i}(3)=4 .^{8}$ The individual contribution schedules can be seen in Appendix A.

Result 1: The proportion of individuals with non-monotonic contribution schedules is substantially higher in the SEQUENTIAL treatment than in the CONTROL treatment, and substantially lower in the ORDERED treatment than in the CONTROL treatment.

\footnotetext{
${ }^{8}$ Such contribution schedules are difficult to reconcile with most models of social preferences as discussed in the previous section. Models of non-linear altruism could provide a justification for non-monotonic contribution schedules. According to these models an individual could contribute more when she believes other contribute low amounts, and less when others contribute more. These models however cannot account for contribution schedules exhibiting multiple "switching points". Most subjects who do not have a weakly monotonic schedule have multiple switching points (9 out of 10 in ORDERED, 25 out of 29 in SEQUENTIAL and 12 out of 15 in CONTOL).
} 
SUPPORT: Figure 1 shows that the proportion of individuals with a non-monotonic contribution schedule is 50.0 percent in CONTROL, 30.3 percent in ORDERED, and 87.9 percent in $S E$ QUENTIAL. A Chi-square test using each individual as an independent observation indicates that the rate of non-monotonic contribution schedules is statistically higher in SEQUENTIAL than in CONTROL $(p$-value $=0.0011)$ and ORDERED $(p$-value $=0.0001)$. While the rate is considerably higher in CONTROL than in the ORDERED (65 percent higher), the difference marginally fails to be significant at a conventional level $(p-$ value $=0.1292) .{ }^{9}$

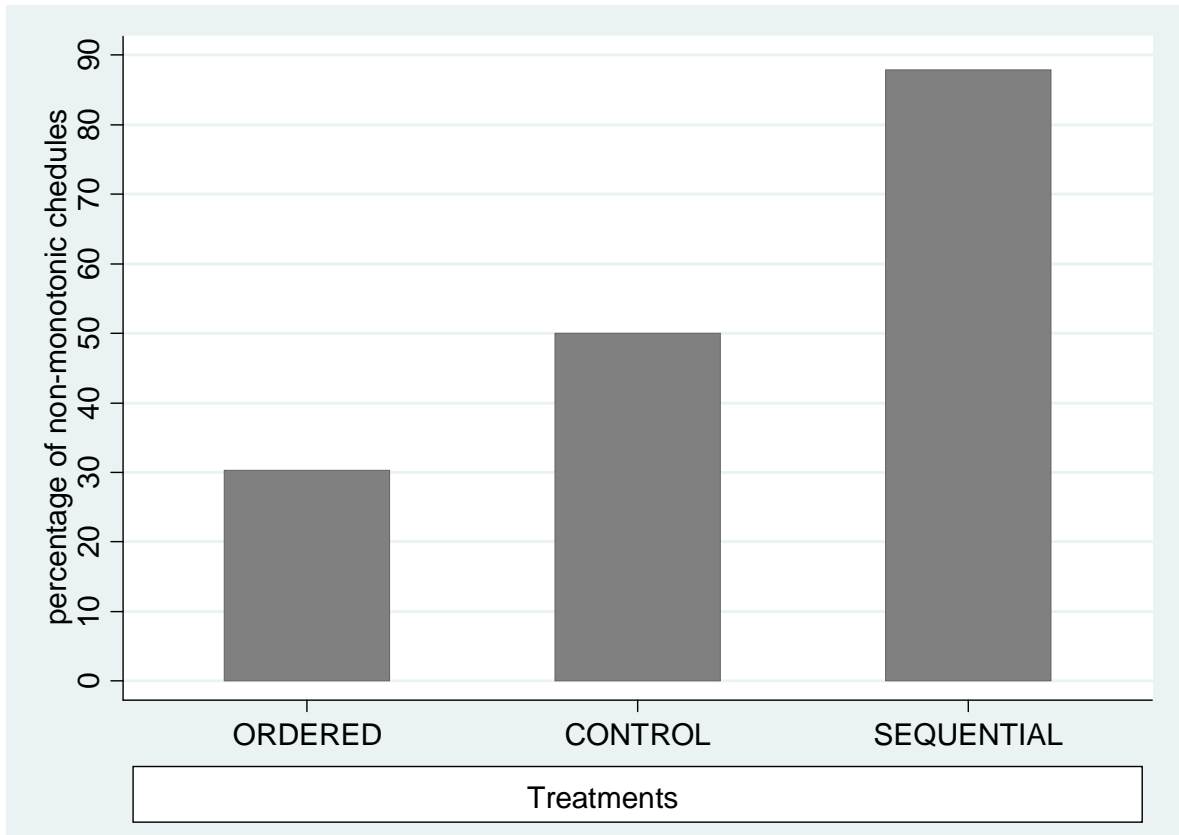

Figure 1: Percentage of subjects with non-monotonic contribution schedules

Result 2: The average number of switches is significantly greater in the SEQUENTIAL than in the CONTROL treatment. The number of switches is not significantly different in the ORDERED and in the CONTROL treatment. Amongst the subjects with non-monotonic contribution schedules, the average number of switches does not differ significantly across treatments.

SUPPORT: The average number of switches is 2.0 in the CONTROL treatment, 3.5 in SEQUENTIAL and 1.2 in ORDERED. Since there are more than two treatments, I first report the results

\footnotetext{
${ }^{9}$ For completeness, I report that the rate of non-monotonic contribution schedules is significantly higher in SEQUENTIAL than in ORDERED ( $p$-value=0.0001).
} 
from a two-tailed Kruskal-Wallis test. I then proceed to pair-wise treatment comparisons only if the Kruskal-Wallis indicates significant differences across treatments. The Kruskal-Wallis test reveals a significant difference across treatments $(p$-value $=0.0001)$. Using a two-tailed Mann-Whitney test with each individual as an independent observation, I find that the difference is significant between CONTROL and SEQUENTIAL and $(p-$ value $=0.0084)$. The difference between CONTROL and ORDERED narrowly misses the 10 -percent level of significance $(p$-value $=0.1084) .{ }^{10}$ Nevertheless, the number of switches amongst individuals with non-monotonic schedules is similar across treatments (3.9 in ORDERED, 4.0 in CONTROL and 4.0 in SEQUENTIAL) and not significantly different (Kruskal-Wallis; $p$-value $=0.8776$ ). This indicates that the difference in the number of switches on average is due to the higher percentage of non-monotonic contribution schedules in SEQUENTIAL (see Result 1).

The greater extent of non-monotonic schedules in SEQUENTIAL may be partly attributed to the fact that individuals cannot revise their choices once made. However, half of the participants also fail to report a weakly monotonic contribution schedule even in CONTROL where revisions are possible. Given the impact of the frames on the monotonicity of contribution schedules, the next subsection investigates whether and how the different frames also affect the predictive power in the one-shot public-good game.

\subsection{Predictive power of schedules in the one-shot public-good game}

A natural way to investigate the predictive power of the contribution schedules is to examine whether the actual contributions of participants in the one-shot game deviate from those in the contribution schedules. Recall that participants were asked to state how much they believed their peers would contribute on average in the one-shot game. Following Fischbacher and Gächter (2010), I use this belief and the contribution schedule to obtain a prediction about how much an individual will contribute in the one-shot game. For example, if someone believes that his peers will contribute on average 5 , the predicted contribution is obtained by looking at the contribution the individual stated he would make if the others contributed 5 on average in the contribution schedule.

Result 3: On average, contribution schedules are accurate predictors of contributions in the oneshot game only in the ORDERED treatment.

SUPPORT: Let Deviation be the difference between a subject's actual and predicted contribution. Figure 2 presents the distribution of Deviation in each treatment. As can be easily seen, relative

\footnotetext{
${ }^{10}$ The difference between SEQUENTIAL and ORDERED is highly significant ( $p$-value $\left.=0.0000\right)$
} 
to the CONTROL treatment, more subjects deviate from the predicted contribution in the $S E$ QUENTIAL treatment, and less in the ORDERED treatment. The average deviation is 1.4 tokens in CONTROL, 1.8 tokens in SEQUENTIAL and 0.2 in the ORDERED. A two-tailed Wilcoxon signed-rank test using each individual as an independent observation indicates that the deviation is not significantly different from 0 in the ORDERED condition ( $p$-value $=0.8266)$, but it is in the CONTROL $(p-$ value $=0.0653)$ and in the SEQUENTIAL treatment $(p-$ value $=0.0047) .{ }^{11}$

The average deviation from the predicted contribution is one obvious indicator for evaluating the predictive power of contribution schedules. In this case, however, it masks the fact that the schedules predict perfectly the contribution of nearly 50 percent of subjects in the CONTROL and $O R D E R E D$ treatments. Figure 2 shows that the relative efficacy of the schedules in $O R D E R E D$ is due to the (roughly) equal number of positive and negative deviations from the predicted contribution. For this reason, next, I investigate the predictive power of the contribution schedules using a different measure.

\footnotetext{
${ }^{11}$ This difference is not statistically significant between SEQUENTIAL and CONTROL ( $p$-value $\left.=0.3300\right)$. Despite the large difference, a Mann-Whitney test fails to reject the hypothesis that average devation is the same in ORDERED and CONTROL ( $p$-value=0.2406). The difference in average devation between ORDERED and SEQUENTIAL is statistically significant $(p-$ value $=0.0375)$.
} 


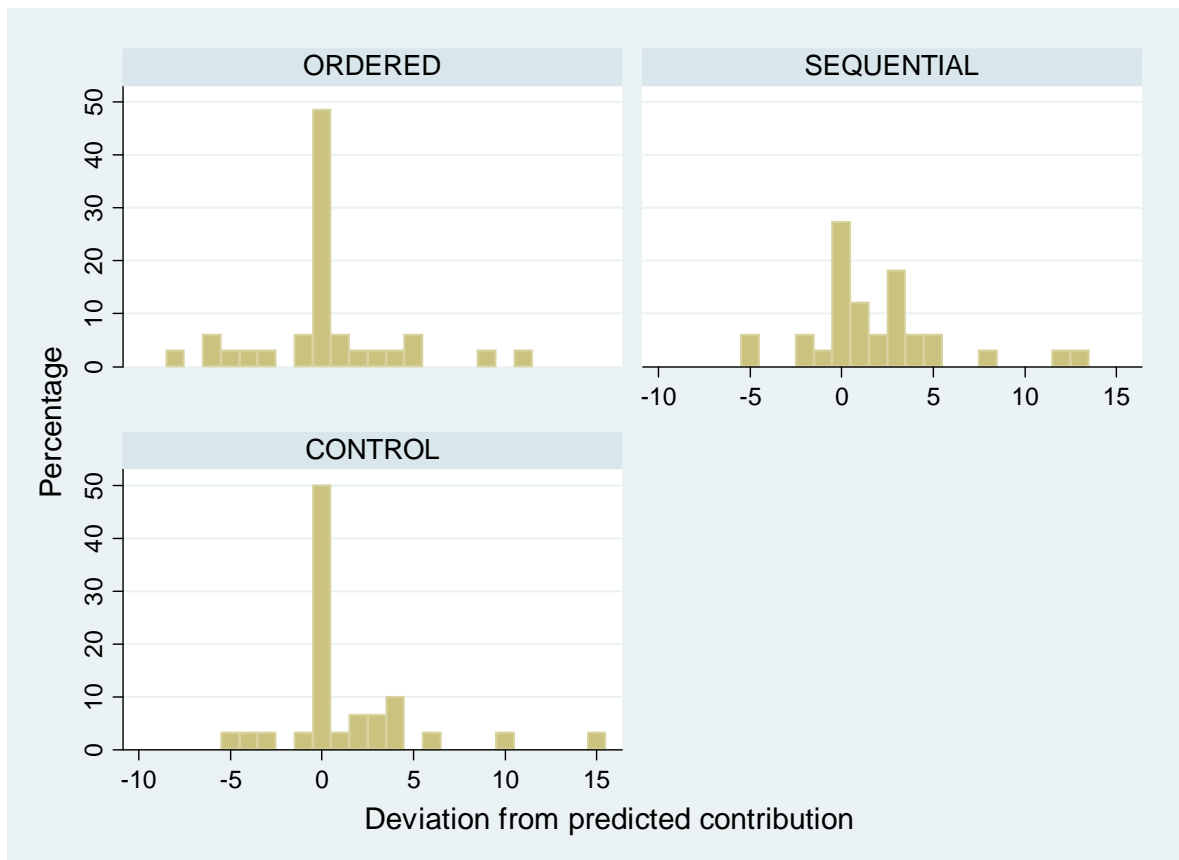

Figure 2: Distribution of deviation from the predicted contribution in the one-shot game.

Result 4: Relative to the CONTROL treatment, the probability an individual's contribution differs from their predicted contribution is higher in SEQUENTIAL, and (insignificantly) lower in ORDERED. This probability of deviation is higher for individuals with noisy contribution schedules and for those with high beliefs about the contribution of their peers.

SUPPORT: Table 1 reports the results from a regression analysis investigating the determinants of an individual's deviation from their predicted contribution. The dependent variable is a binary variable taking the value of 1 if Deviation $\neq 0$ and the value of 0 if Deviation $=0$. Model 1 includes only treatment dummies as regressors (CONTROL being the omitted category). The regression shows that the probability of deviating from the predicted contribution is 22.6 percent higher in SEQUENTIAL than in CONTROL ( $p$-value=0.050). The difference between CONTROL and ORDERED is small (1.5 percent) and statistically insignificant ( $p$-value=0.904). Model 2 includes the variable "Switcher" as an explanatory variable. Switcher is a dummy variable taking the value of 1 if the contribution schedule of a particular individual includes more than 1 switches. ${ }^{12}$

\footnotetext{
${ }^{12}$ The rationale for this is that, as mentioned earlier, none of the standard models of social preference can account for more than one switches. Note that "triangle" contributors have one switch in their contribution schedules.
} 
Model 2 indicates that the probability a "switcher" deviates from his predicted contribution is 31.38 percent higher than that of a non-switcher $(p-$ value $=0.003)$. The fact that the size of the SEQUENTIAL coefficient is approximately halved and is no longer significantly different from zero $(p-$ value $=0.326)$ indicates that the difference across the two treatments is mainly due to the higher number of individuals with non-monotonic contribution schedules in this treatment. To test this explanation further, I ran a regression which in addition to the regressors in Model 2, included interaction terms between the treatment and switcher dummies (not reported). The only significant variable in this regression is the Switcher variable (marg. effect: 36.27 percent; $p$-value=0.047). The coefficient for SEQUENTIAL is slightly lower than in Model 2 and remains statistically insigificant (marg. effect: 10.78 percent; $p$-value=0.591). The fact that the interaction terms are insignificant indicates the switchers are as likely to deviate from the predicted contribution in all treatments and corroborates Result 2. Model 3 adds an individual's Belief as a regressor. The results indicate that the higher the belief of an individual about the average contribution of his peers, the higher is the probability they deviate from their predicted contribution (marginal effect: 3.22 percent; $p$-value $=0.005$ ). This seems intuitive. For example, while an individual may have stated that she would contribute 15 if she knew for sure that others did the same (strategy method), in the one-shot game, she cannot be sure whether this will be the case. Therefore, she may be more likely to deviate from her predicted contribution than if she believed others would contribute 5. The reason is that participants, on average, contribute less than their beliefs. Therefore, the extent of the deviation is lower when beliefs are low. A similar finding regarding beliefs is also reported in Fischbacher and and Gächter (2010). Finally, Model 4 replaces the Switcher dummy variable with the total number of switches in an individual's contribution schedule. As can be seen, the higher the number of switches in a contribution schedule, the higher is the probability that an individual deviates from his predicted contribution $\left(p\right.$-value=0.015). ${ }^{13}$ The marginal effect shows that an additional switch in the contribution schedule increases the probability of deviating from the predicted contribution by 6.21 percent.

\subsection{Predictive power of schedules in the finitely-repeated public-good game}

The approach for evaluating the predictive power of the contribution schedules in the finitelyrepeated game is the same as in the previous section. In each of the ten periods, I estimate an

\footnotetext{
${ }^{13}$ The results are qualitatively unaffected if we use dummies to control for the number of switches instead of the total number of switches.
} 


\begin{tabular}{ccccc}
\hline \hline Model & 1 & 2 & 3 & 4 \\
\hline \hline ORDERED & 0.0147 & 0.0588 & 0.0678 & 0.0872 \\
& $(0.1227)$ & $(0.1252)$ & $(0.1299)$ & $(0.1303)$ \\
SEQUENTIAL & $0.2263^{* *}$ & 0.1273 & 0.1219 & 0.1414 \\
& $(0.1153)$ & $(0.1296)$ & $(0.1336)$ & $(0.1300)$ \\
Switcher & & $0.3138^{* * *}$ & $0.2933^{* * *}$ & \\
& & $(0.1041)$ & $(0.1089)$ & \\
Beliefs & & & $0.0322^{* * *}$ & $0.0308^{* * *}$ \\
& & & $(0.0113)$ & $(0.0113)$ \\
Totalswitch & & & & $0.0621^{* *}$ \\
& & & & $(0.0255)$ \\
\hline Observations & 96 & 96 & 96 & 96 \\
\hline \hline
\end{tabular}

Table 1: Probability of deviating from predicted contribution in the one-shot game. Probit regression. Entries are marginal effects. Standard errors are in parentheses. ${ }^{*}$ p-value $<0.1,{ }^{* *}$ pvalue $<0.05,{ }^{* * *}$ p-value $<0.01$

individual's Deviation by comparing their actual to their predicted contribution. ${ }^{14}$

Result 5: Contribution schedules accurately predict contributions in the finitely-repeated game in the CONTROL and the ORDERED treatments, but not in the SEQUENTIAL treatment.

SUPPORT: Figure 3 presents the distribution of Deviation in each treatment. As can be seen, more subjects appear to deviate from their predicted contribution in the SEQUENTIAL than in the CONTROL treatment. The CONTROL and ORDERED treatments give similar results. The average deviation across the 10 periods is 0.3 in CONTROL, - 0.6 in the ORDERED, and 1.4 in SEQUENTIAL. To control for the panel nature of the data in the third part of the experiment, I ran a linear regression controlling for random effects at the session level. The average deviation is significantly different from zero in SEQUENTIAL ( $p$-value=0.003), but not in CONTROL and ORDERED ( $p$-value $=0.637$ and 0.322 , respectively).${ }^{15}$ These results are robust if I evaluate behavior at different points of part 3 , such as in period 1 and the first five periods.

\footnotetext{
${ }^{14}$ Note that participants received feedback about the contributions of their peers and their private earnings at the end of each period, but also at the start of the first period (i.e., regarding decisions in the one-shot game).

${ }^{15}$ Average deviation is signficantly different between SEQUENTIAL and CONTROL ( $p$-value=0.081), and between ORDERED and SEQUENTIAL ( $p$-value=0.005). Average devation is not significantly different between ORDERED and CONTROL ( $p$-value $=0.302)$.
} 




Figure 3: Distribution of deviation from the predicted contribution in the finitely-repeated game

Result 6: The probability an individual's contribution differs from their predicted contribution in the finitely-repeated game is higher in SEQUENTIAL than in CONTROL. The difference between CONTROL and ORDERED is not statistically significant. The probability of deviating from the predicted contribution is higher for individuals with noisy contribution schedules and with high beliefs about the contribution of their peers.

SUPPORT: Table 2 reports the results from a regression analysis investigating the determinants of an individual's deviation from their predicted contribution. The dependent variable, as in the previous subsection, is a binary variable taking the value of 1 if Deviation $\neq 0$ and the value of 0 if Deviation $=0$ for a given subject in a given period. Given the interdependence of contributions at the session level, the model controls for random effects at the session level. The logic of the empirical investigation is the same as in the previous section for the one-shot game, building the model up gradually.

The results in Table 2 are qualitatively the same as those in Table 1 for the one-shot game. The regression shows that the probability of a subject deviating from her predicting contribution is 29.5 percent higher in the SEQUENTIAL than in the CONTROL treatment ( $p$-value $<0.001)$. 
Contributions in the ORDERED treatment are 4.9 percent less likely to differ from the predicted contribution than in the CONTROL treatment, but the difference is far from being statistically significant $(p$-value=0.427). Model 2 shows that a "Switcher", that is, an individual with noisy contribution schedule is 28.2 percent more likely to deviate from his predicted contribution $(p$-value $<0.001)$. However, unlike in the one-shot game, the coefficient for SEQUENTIAL remains significant in Model $2(p$-value=0.002), although the coefficient drops from 28.2 to 21.1 percent. Model 3 controls for an individual's Belief about other's contribution. Similar to the oneshot game, the higher the belief of an individual about the average contribution of her peers, the higher is the probability she deviates from her predicted contribution (marg. effect: 4.7 percent; $(p-$ value $<0.001)$. Note that the coefficient for SEQUENTIAL is no longer significant in Model 3. This indicates that the higher rate of deviations in this treatment is mostly due to the higher beliefs about the contributions of others. ${ }^{16}$ Model 4 replaces the Switcher variable with the total number of switches in an individual's contribution schedule, and adds a (linear) control for time effects. The results indicate that the higher the number of switches in a contribution schedule, the higher is the probability that an individual deviates from his predicted contribution $(p-$ value $<0.001)$. The marginal effect shows that, similar to the one-shot game, an additional switch in the contribution schedule increases the probability of deviating from the predicted contribution by 6 percent. The probability of deviating from one's predicted contribution decreases by 1 percent in every period. The reason is that, as in all public-good experiments, contributions decline over time. As we will see in the next subsection, most people contribute small amounts in response to low contribution by their peers.

\subsection{Cooperation preferences, contribution levels and beliefs}

So far, the analysis has focused on how the different frames affect the monotonicity and predictive power of the contribution schedules. In this section, I investigate the impact of the different frames on the levels of contribution in the three parts of the experiment and subjects' beliefs. Before doing this, however, I will examine how the frames impact the different types of cooperation preferences seen in previous studies. Fischbacher, Gächter and Fehr (2001) proposed a classification of the

\footnotetext{
${ }^{16}$ To test this explanation, I ran a regression separately for each treatment with the sole regressors being Switcher and Belief. The latter is always statistically significant, while the former is signficant in all treatments except in the SEQUENTIAL. A closer inspection at the data indicates the both switchers and non-switchers have substantially higher levels of beliefs in this treatment. As a result, both are about 75 percent likely to deviate from their predicted contribution - a rate which is considerably higher than in the other treatments. I discuss the impact of framing on contributions and beliefs in more detail in the next subsection.
} 


\begin{tabular}{ccccc}
\hline \hline Model & 1 & 2 & 3 & 4 \\
\hline \hline ORDERED & -0.0492 & -0.0127 & -0.03480 & -0.0154 \\
& $(0.0620)$ & $(0.0725)$ & $(0.0576)$ & $(0.0592)$ \\
SEQUENTIAL & $0.2950^{* * *}$ & $0.2112^{* * *}$ & 0.0646 & 0.0717 \\
& $(0.0558)$ & $(0.0690)$ & $(0.0610)$ & $(0.0616)$ \\
Switcher & & $0.2822^{* * *}$ & $0.2649^{* * *}$ & \\
& & $(0.0346)$ & 0.0356 & \\
Beliefs & & & $0.0474^{* * *}$ & $0.0486^{* * *}$ \\
& & & $(0.0059)$ & $(0.0063)$ \\
Totalswitch & & & & $0.0603^{* * *}$ \\
& & & & $(0.0079)$ \\
Period & & & & $0.0107^{*}$ \\
& & & & $0.0063)$ \\
\hline Observations & 960 & 960 & 960 & 960 \\
\hline \hline
\end{tabular}

Table 2: Probability of deviating from predicted contribution in the finitely-repeated game. Probit regression with random effects at the session level. Entries are marginal effects. Standard errors are in parentheses. ${ }^{*}$ p-value $<0.1,{ }^{* *}$ p-value $<0.05,{ }^{* * *}$ p-value $<0.01$

different patterns observed in the contribution schedules. In particular, individuals that always contribute zero in the strategy method, irrespective of the contribution of their peers, are classified as "free riders". Individuals who have a contribution schedule with either a weakly monotonic pattern with at least one increase or a positive Spearman rank correlation significant at the 1percent level are classified as "conditional cooperators". ${ }^{17}$ "Triangle contributors" are participants who have a significantly increasing schedule up to some maximum and a significantly decreasing schedule thereafter, using again as a criterion the Spearman rank test at the 1-percent level of significance. Participants that could not be classified in one of the above categories are classified as "others" or "confused".

\begin{tabular}{cccc}
\hline \hline Treatments/types in percent & CONTROL & ORDERED & SEQUENTIAL \\
\hline \hline Free Riders & 30.00 & 36.36 & 3.03 \\
Conditional Cooperators & 43.33 & 39.39 & 78.79 \\
Triangles & 3.33 & 3.03 & 0.00 \\
Others & 23.33 & 21.21 & 18.18 \\
\hline \hline
\end{tabular}

Table 3 : Type classification in percentage

${ }^{17}$ Note that conditional cooperators can have non-monotonic schedules and, indeed, some of them did. 
Result 7: The sequential frame has a pronounced impact on the elicited contribution schedules relative to the CONTROL treatment. In contrast, the ordering of the others' contribution does not affect the elicited contribution schedules.

SUPPORT: Table 3 presents the results of the FGF classification method in each treatment. While the distribution of types appears to be similar in CONTROL and ORDERED, it is strikingly different in SEQUENTIAL. As can be seen, only 1 out of 33 participants (3 percent) can be classified as selfish in the SEQUENTIAL treatment, compared to 12 out of 33 in the ORDERED treatment (36.4 percent), and 9 out of 30 in the CONTROL treatment (30 percent). Similarly, 43 percent of individuals are classified as conditional cooperators in the CONTROL treatment, 39.4 percent in ORDERED, and 78.8 percent in SEQUENTIAL. ${ }^{18}$ A Fischer's exact test rejects the hypothesis that the distribution of types is the same across the three treatments ( $p$-value $=0.003$ ). Pairwise Fischer exact tests reveal that this difference is due to the SEQUENTIAL treatment. In particular, the difference between $C O N T R O L$ and SEQUENTIAL is significant ( $p$-value $=0.004$ ), while that between ORDERED and CONTROL is not ( $p$-value $=0.947)$.

\footnotetext{
${ }^{18} \mathrm{It}$ is also worthwhile pointing out that only 3 of the 13 individuals classified as conditional cooperators in $O R$ DERED have a non-monotonic contribution schedule. In contrast, 8 of 13 conditional cooperators in CONTROL, and 24 of the 26 in SEQUENTIAL have non-monotonic schedules. The proportion of conditional cooperators with non-monotonic schedules, relative to the CONTROL treatment, is lower in ORDERED ( $p$-value $=0.0183)$ and higher in SEQUENTIAL ( $p$-value=0.03). Conditional cooperators are switching more often on average in SEQUENTIAL (3.0 switches) and CONTROL (2.1 switches) compared to ORDERED (0.5 switches). A Mann-Whitney test indicates that the difference between $O R D E R E D$ vs $C O N T R O L$ is statistically significant $(p-$ value $=0.0398)$, while that between CONTROL and SEQUENTIAL is not $(p-$ value $=0.1239)$.
} 


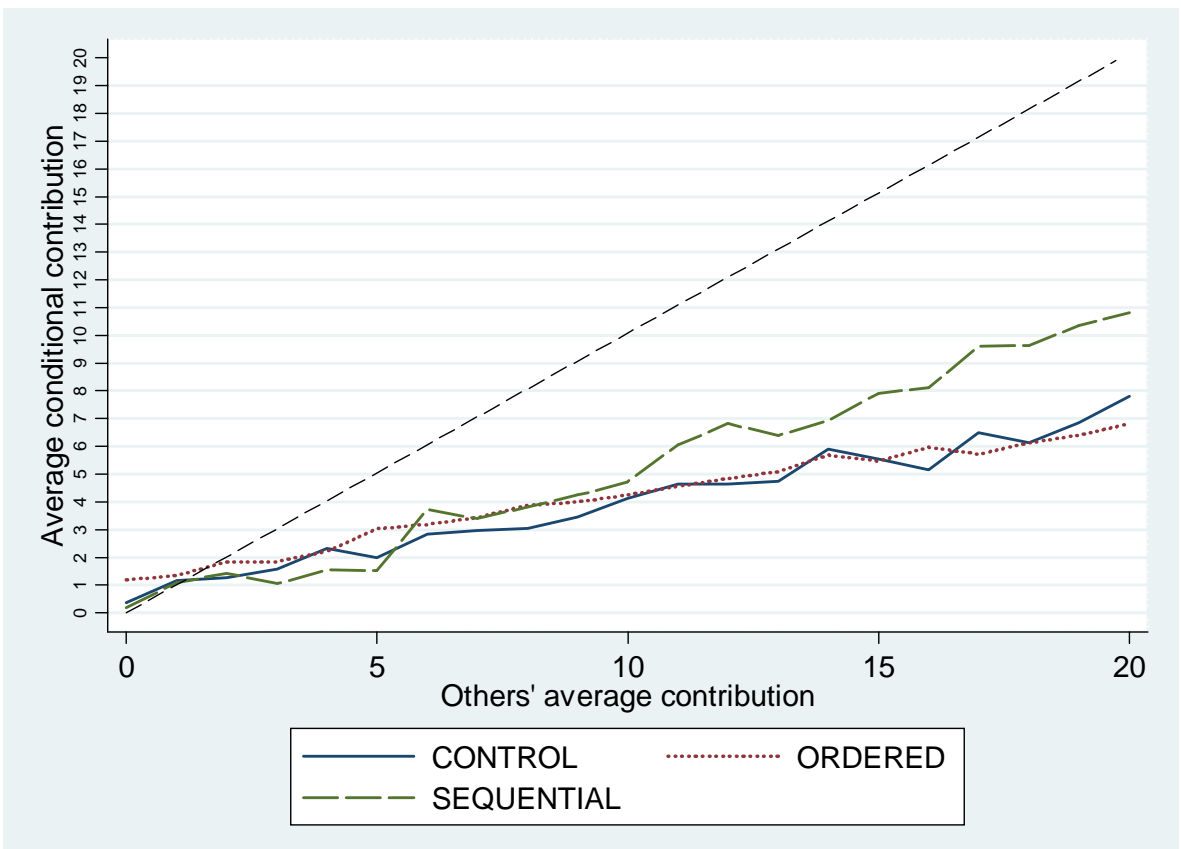

Figure 4: Average conditional contribution in strategy method

Additional support for Result 7 can be found in Figure 4 and Table $4 .{ }^{19}$ Figure 4 presents the average conditional contribution in the first part of the experiment. Similar to previous experiments, the average conditional contribution is monotonically increasing and lies below the 45-degree line in all treatments. However, as can be seen, conditional contributions tend to be higher in SEQUENTIAL, than in the other two treatments. The results of a linear regression with individual random effects reported in Table 4 confirm that the average conditional contribution differs significantly in SEQUENTIAL. In particular, the slope of the conditional contribution is higher by 20.9 degrees in SEQUENTIAL than in CONTROL. This difference is non-trivial and statistically significant $(p-$ value $<0.001)$. It implies that for every additional token contributed to the public account by one's peers, the contribution will be 0.209 higher than in the CONTROL. The difference in slopes between CONTROL and ORDERED is smaller (5.2 degrees) and narrowly misses the 10-percent level of significance $(p-$ value $=0.101)$.

Result 8: By and large, beliefs and unconditional contributions are not significantly different

\footnotetext{
${ }^{19}$ Figure 4 and Table 4 below excludes subject 1202 who gave 20 when others gave 0 and had a Spearman correlation coefficient of -1
} 


\begin{tabular}{cc}
\hline \hline Model & 1 \\
\hline \hline Others' contribution & $0.3320^{* * *}$ \\
& $(0.2296)$ \\
ORDERED & 0.7085 \\
& $(1.0552)$ \\
SEQUENTIAL & -0.0320 \\
& $(1.0474)$ \\
ORDERED * Others' contribution & -0.0524 \\
& $(0.0319)$ \\
SEQUENTIAL * Others' contribution & $0.2087^{* * *}$ \\
& $(0.0317)$ \\
Constant & 0.6331 \\
& 0.7580 \\
\hline \hline
\end{tabular}

Table 3: Determinants of conditional contribution in the strategy method. Linear regression with individual random effects. ${ }^{*}$ p-value $<0.1,{ }^{* *}$ p-value $<0.05,{ }^{* * *}$ p-value $<0.01$

across treatments in the first and second part of the experiment. Contributions are higher in the finitely-repeated game in SEQUENTIAL, due to higher beliefs about the contributions of others.

SUPPORT: [FIRST PART OF THE EXPERIMENT] The average belief regarding others' average (unconditional) contribution in the first part of the experiment is 7.16 (CONTROL), 5 (ORDERED), and 8 (SEQUENTIAL). A Kruskal-Wallis test rejects the hypothesis that beliefs are the same across treatments $(p-$ value $=0.0408)$. Using a two-tailed Mann-Whitney test with each individual as an independent observation, the difference between CONTROL and ORDERED is marginally statistically significant $(p$-value $=0.0999)$, while that between CONTROL and SEQUENTIAL is not $(p-$ value $=0.6265)$. In contrast, a Kruskal-Wallis test fails to reject the hypothesis that subjects' unconditional contributions $(6.23,4.42,6.57$, in CONTROL, ORDERED and SEQUENTIAL, respectively) are the same across treatments in the first part of the experiment $(p-$ value $=0.1413)$.

[SECOND PART OF THE EXPERIMENT] A Kruskal-Wallis test fails to reject the hypothesis that subjects' beliefs $(6.03,5.81,6.72$, in CONTROL, ORDERED and SEQUENTIAL, respectively) are the same across treatments $(p-$ value $=0.6003)$. While the test rejects the same hypothesis for contributions $(4.93,3.85,5.82$, in CONTROL, ORDERED and SEQUENTIAL, respectively; $p$-value $=0.0703$ ), a two-tailed Mann-Whitney test with each individual as an independent observation indicates that neither the difference between CONTROL and ORDERED is statistically significant $(p-$ value $=0.3170)$ nor is that between $C O N T R O L$ and SEQUENTIAL $(p-$ value $=0.2714)$. 




Figure 5: Average contribution over time

[Third Part of the experiment] As can be seen in Figure 5, while contributions appear to be very similar across all periods in CONTROL and ORDERED, contributions tend to be higher in the SEQUENTIAL treatment than in the CONTROL. In particular, average contribution is 1.7 in CONTROL, 1.8 in ORDERED and 4.3 in SEQUENTIAL. Similarly, on average, beliefs are higher in SEQUENTIAL (5.5), than in CONTROL (2.12) and ORDERED (2.42). This seems surprising given that beliefs and contributions did not differ significantly in the first two parts of the experiment (Result 7). The difference appears already in the first period of the third part where beliefs in SEQUENTIAL are 6.2, 3.8 in CONTROL, and 4.8 in ORDERED. Given the panel nature of the data and the use of random matching in this part of the experiment, to compare behavior across treatments Table 5 presents the results from a linear regression with random effects at the session level. Model 1 illustrates that the difference between CONTROL and SEQUENTIAL is statistically significant ( $p$-value $=0.005)$, but not that between $C O N T R O L$ and ORDERED ( $p$-value=0.945). The addition of subjects' beliefs as an explanatory variable in Model 2 indicates that once I control for beliefs, the difference between CONTROL and SEQUENTIAL is no longer significant ( $p$-value $=0.921$ ). The coefficient of subjects' beliefs is highly significant $(p$-value $<0.001)$ and indicates that a one unit increase in beliefs, increases the con- 


\begin{tabular}{cccc}
\hline \hline Model & 1 & 2 & 3 \\
\hline \hline ORDERED & 0.0708 & -0.1913 & -0.01871 \\
& $(1.0328)$ & $(0.2533)$ & $(0.3622)$ \\
SEQUENTIAL & $2.8676^{* *}$ & -0.0276 & -0.2773 \\
& $(1.0328)$ & $(0.2780)$ & $(0.4298)$ \\
Period & $-0.2035^{* * *}$ & 0.0201 & 0.0167 \\
& 0.0433 & $(0.0369)$ & $(0.0374)$ \\
Beliefs & & $0.8011^{* * *}$ & $0.7678^{* * *}$ \\
& & $(0.0342)$ & $(0.1094)$ \\
Beliefs * ORDERED & & & 0.0025 \\
Beliefs * SEQUENTIAL & & & $(0.1190)$ \\
& & & 0.0660 \\
Constant & $2.8173^{* * *}$ & -0.0793 & $0.1184)$ \\
& $(0.7697)$ & 0.0099 \\
Observations & 960 & 960 & $0.3890)$ \\
\hline \hline
\end{tabular}

Table 4: Determinants of contributions in the finitely-repeated game. Linear regression with session random effects. ${ }^{*}$ p-value $<0.1,{ }^{* *}$ p-value $<0.05,{ }^{* * *}$ p-value $<0.01$

tribution of an individual by 0.80 tokens. Finally, Model 3 shows that the relationship between beliefs and contributions is similar across treatments. This implies that higher beliefs about others' contribution drive the higher levels of contribution in SEQUENTIAL. In Appendix B, I provide additional evidence from a regression analysis of subjects' beliefs. I show that the higher beliefs in SEQUENTIAL are due to a stronger relationship between contributions in parts 1 and 2 (i.e., the feedback subjects receive at the start of part 3), and beliefs. It is difficult to explain why the sequential frame has the effect on belief formation.

\section{Discussion}

The aim of the experiment was to evaluate the sensitivity of cooperation preferences to changes in the frame which have been recently shown to affect the elicitation of (risk) preferences (LevyGarboua et al., 2012). In particular, using the method of Fischbacher, Gächter and Fehr (2001; FGF) for eliciting cooperation preferences, I varied $(i)$ the order in which others' contributions appeared in the experiment, and (ii) whether these contributions were presented simultaneously or in sequence. In addition, the experiment aimed to evaluate the predictive power of cooperation preferences in a one-shot and a finitely-repeated public-good game. In general, I found that the 
order in which the contributions of others was presented had no impact on the elicited preferences and their predictive power. However, presenting the contributions of others in a sequence had a significant effect on the elicited preferences and reduced their predictive power. In this sense, my findings are similar to those of Levy-Garboua et al. (2012) who found that risk preferences are affected more by changes in whether the options are presented sequentially or simultaneously, rather than the order in which the options are presented. Overall, elicited preferences are more accurate at predicting behavior when others' contributions are presented simultaneously and in ascending order, like in Fischbacher, Gächter and Fehr (2001).

What could explain the impact of the sequential frame in our experiment? One explanation for the number of non-monotonic schedules in SEQUENTIAL may be that individuals cannot revise their choices once made. While this explanation can partly account for the level of noise in the contribution schedules, it cannot account for the much higher levels of conditional cooperation and near absence of free riders seen in this treatment. An explanation for this finding may be that individuals wish to maintain a positive self-image. Gneezy et al. (2011) found that donations to charity are more likely to happen after people lie or fail to return money they had received by mistake. The authors discuss the concept of "conscience accounting" which means that people try to compensate "bad" activities to protect their identity and self-image". It seems possible that making 21 consecutive decisions not to contribute to the public account may be more damaging for one's self image than submitting once a table with zero contributions.

An issue which may be interesting for future study is when cooperation preferences are elicited. Fischbacher and Gächter (2010) ran experiments with the FGF strategy method either at the start or the end of the experiment to evaluate whether the timing of the elicitation affected contributions in a finitely-repeated game. They found that this was not the case and that contributions were the same when cooperation preferences were elicited at the start and the end of the experiment. This finding is the reason I elicited preferences only at the start of the experiment. However, the finding that beliefs and contributions in the finitely-repeated game are higher in SEQUENTIAL suggests that eliciting cooperation preferences at the start of the experiment may influence outcomes, at least under some frames. Therefore, it may be useful for future studies to randomize when the strategy method is administered.

Finally, given the findings from the present experiment, I believe that the FGF method could be used to investigate whether other kinds of frames that have been shown to affect contributions in public-good games, such as the warm-glow/cold-prickle effect of Andreoni (1995) and the labelling of the game or strategies (e.g., Ellingsen et al., 2012; Kay and Ross, 2003; Liberman et al., 2004; Ross and Ward, 1996) affects only subjects' beliefs, as suggested in previous articles (Dufwenberg et al. 2011; Ellingsen et al., 2012; Nikiforakis, 2010) or also cooperation preferences. 


\section{References}

[1] Andreoni J., (1995). "Warm-Glow Versus Cold-Prickle: The Effects of Positive and Negative Framing on Cooperation in Experiments." Quarterly Journal of Economics, 110, 1-21.

[2] Bolton G.E., Ockenfels A., (2000). "A Theory of Equity, Reciprocity, and Competition." American Economic Review, 90(1), 166-193.

[3] Bougherara D., Denant-Boemont L., Masclet D., (2011). "Cooperation and framing effects in provision point mechanisms: Experimental evidence." Ecological Economics, 70(6),1200-1210.

[4] Brandts J., Charness G., (2000). "Hot vs. Cold: Sequential responses and preference stability in experimental games." Experimental Economics, 2, 227-238.

[5] Brandts J., Schwieren C., (2007). "Frames and Games." working paper, Insitut d'anàlisi Econòmia and University of Heidelberg

[6] Brewer M.B., Kramer Mr., (1986). "Choice behavior in social dilemmas: Effects of social identity, group size, and decision framing." Journal of Personality and Social Psychology, 50, 543-549.

[7] Brosig J., Weimann J., Yang C.L., (2003). "The Hot versus Cold Effect in a Simple Bargaining Experiment." Experimental Economics, 6, 75-90.

[8] Burlando R., Guala F., (2005). "Heterogeneous Agents in Public Goods Experiments." Experimental Economics, 8, 35-54.

[9] Cheung S. L., (2012)."New Insights into Conditional Cooperation and Punishment from a Strategy Method Experiment." IZA Discussion Papers 5689, Institute for the Study of Labor (IZA).

[10] Cookson R., (2000). "Framing Effect in Public Goods Experiments." Experimental Economics, 3, 55-79.

[11] Cubitt R., Drouvelis M., Gächter S., (2011). "Framing and Free Riding: Emotional Responses and Punishment in Social Dilemma Games." Experimental Economics, 14, 254-272.

[12] Dufwenberg M., Gächter S., Hennig-Schmidt H., (2011). "The Framing of Games and the Psychology of Play." Games and Economics Behavior,73(2), November 2011, 459-478. 
[13] Ellingsen T., Johannesson M., Mollerstrom J., \& Munkhammar S., (2012). "Social Framing Effects: Preferences or Beliefs?" Games and Economic Behavior, 76, 117-130.

[14] Fehr E., Schmidt K.M., (1999). "A Theory Of Fairness, Competition, And Cooperation." The Quarterly Journal of Economics,114(3), 817-868.

[15] Fischbacher U., Gächter S., Fehr E., (2001). "Are people Conditionally Cooperative? Evidence from a Public Goods Experiment." Economics Letters, 71(3), 397-404.

[16] Fischbacher U., Gächter S., (2010). "Social Preferences, Beliefs and the Dynamics of Free Riding in Public Good experiments." American Economic Review, 100, 541-556.

[17] Fosgaard T., Gårn Hansen L.,Wengström E., (2011). "Framing and Misperceptions in a Public Good Experiment." FOI Working Paper 2011/11, University of Copenhagen, Institute of Food and Resource Economics.

[18] Gneezy U., Imas A., Madarasz K.,(2011). "Conscience Accounting: Emotional Dynamics and Social Behavior." Working paper.

[19] Gueth W., Huck S., Mueller W., (2001). "The Relevance of Equal Splits in Ultimatum Games." Games and Economic Behavior, 37, 161-169.

[20] Herrman B., Thöni C., (2009). "Measuring Conditional Cooperation: A Replication Study in Russia." Experimental Economics, 12(1), 87-92.

[21] Kay A. C.,Ross L., (2003). "The perceptual push: the interplay of implicit cues and explicit situational construals on behavioral intentions in the Prisoner's dilemma." Journal of Experimental Social Psychology, 39, 634-643.

[22] Kocher M.,Cherry T., Kroll S., Netzer R and Sutter M., (2008). "Conditional cooperation on three continents." Economics Letters, 101(3), 175-78.

[23] Kotani K., Managi S., Tanaka K., (2008). "Further investigations of framing effects on cooperative choices in a provision point mechanism." Economics Bulletin, 51(3), 1-9.

[24] Lévy-Garboua L., Maafi H.,Masclet D.,Terracol A., (2012). "Risk aversion and framing effects." Experimental Economics, 15, 128-144.

[25] Liberman V., Samuels S M., \& Ross L., (2004). "The name of the game: predictive power of reputations versus situational labels in determining prisoner's dilemma game moves." Personality and Social Psychology Bulletin, 30, 1175-1185. 
[26] McCusker C., Carnevale P.J., (1995). "Framing in resource dilemmas: loss aversion and the moderating effects on sanctions." Organizational Behavior and Human Decision Processes, 61, 190-201.

[27] McDaniel W. C., Sistrunk F., (1991). "Management dilemmas and decisions: impact of framing andanticipated responses." Journal of Conflict Resolution, 35, 21-42.

[28] McElroy T., Seta JJ., (2003). "Framing effect: An Analytic-Holistic Perspective." Journal of Experimental Social Psychology, 39, 610-617.

[29] Muller L., Sefton M., Steinberg R., Vesterlund L., (2008). "Strategic Behavior and Learning in Repeated Voluntary Contribution Experiments." Journal of Economic Behavior and Organization, 67, 782-793.

[30] Nikiforakis N., (2010). "Feedback, Punishment and Cooperation in Public Good Experiments." Games and Economic Behavior 68, 689 -702.

[31] Park E.S., (2000). "Warm-Glow Versus Cold-Prickle: A Further Experimental Study of Framing Effects on Free Riding". Journal of Economic Behavior and Organization, 43, 405-421.

[32] Rege M.,Telle K., (2004). "The impact of social approval and framing on cooperation in public good situations." Journal of Public Economics, 88, 1625-1644.

[33] Ross, L., Ward, A., (1996). Naive Realism in Everyday Life: Implications for Social Conflict and Misunderstanding. In Reed, E. S., et al., (Eds.), Values and Knowledge. Lawrence Erlbaum Associates, Mahwah, New Jersey.

[34] Rustagi D., Engel S., Kosfeld M., (2010). "Conditional Cooperation and Monitoring Explain Success in Forest Commons Management." Science, 330, 961-965.

[35] Sell J., Son Y., (1997). "Comparing Public Goods and Common Pool Resources: Three experiments." Social Psychology Quaterly, 60, 118-137.

[36] Selten R., (1967). "Die Strategiemethode Zur Erforschung Des Eingeschränkt Rationalen Verhaltens Im Rahmen Eines Oligopolexperimentes." In Beiträge Zur Experimentellen.

[37] Sonnemans J., Schram A., Offerman T., (1998). "Public good provision and public bad prevention: the effect of framing." Journal of Economic Behavior and Organization, 34, 143-161.

[38] Thöni C., Tyran J., Wengström E., 2012. "Microfoundations of Social Capital." Journal of Public Economics, 96 (7), 635-643. 
[39] Tversky A., Kahnemann D., (1981). "The Framing of Decisions and the Psychology of Choice." Science, 211, 453-458.

[40] van Dijk E., Wilke H., (2000). "Decision-induced focusing in social dilemmas: Give-some, keep-some take-some, and leave-some dilemmas." Journal of Personality and Sociallogy, 78, 92-104.

[41] Volk S., Thöni C., Ruigrok W., (2012). "Temporal Stability and Psychological Foundations of Cooperation Preferences." Journal of Economic Behavior and Organization, 81,664-676.

[42] Willinger M., Ziegelmeyer A., (1999). "Framing and cooperation in public good games: an experiment with an interior solution." Economics letters, 65, 323-328. 
$[43]$

\section{Appendix A: Individual contribution schedules}
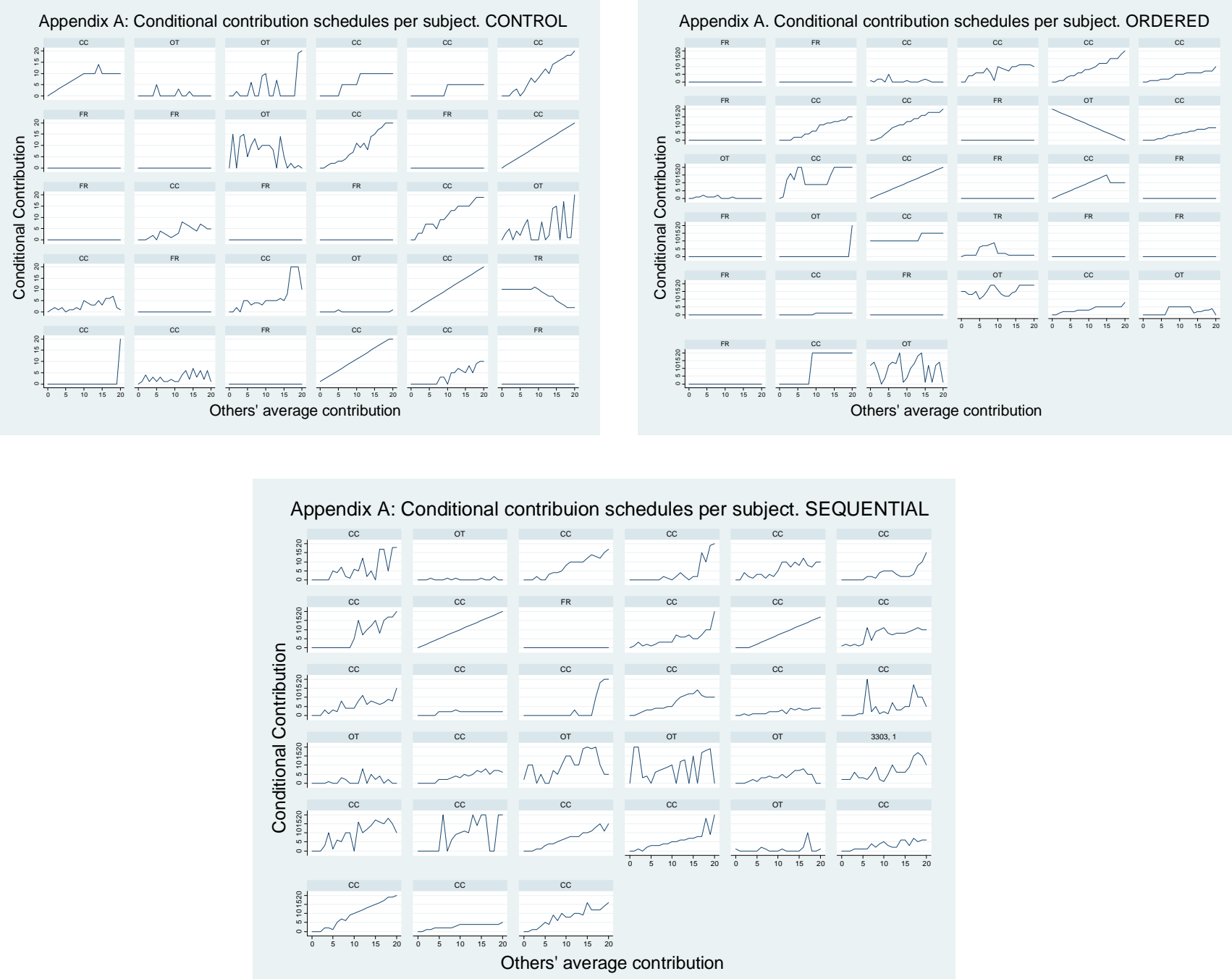

Figure A1: Individual contribution schedules

The letters on top of each subgraph indicate how that particular individual was classified (CC: conditional cooperator; FR: free rider; TR: triangle; OT: other) 


\section{Appendix B: Determinants of beliefs in the finitely-repeated game}

\begin{tabular}{cccc}
\hline \hline Treatments & CONTROL & ORDERED & SEQUENTIAL \\
\hline \hline Period & $-0.2375^{* * *}$ & $-0.3487^{* * *}$ & $-0.2477^{* * *}$ \\
& $(0.0302)$ & $(0.0606)$ & $(0.0570)$ \\
Average Contribution in SM & $0.0912^{* * *}$ & 0.0003 & $0.2371^{* * *}$ \\
& $(0.0207)$ & $(0.0690)$ & $(0.0639)$ \\
Average Contribution in One-Shot & $0.1343^{* * *}$ & $0.2927^{* * *}$ & $0.4484^{* * *}$ \\
& $(0.0517)$ & $(0.0524)$ & $(0.0582)$ \\
Constant & $2.1949^{* * *}$ & $3.2171^{* * *}$ & $2.6695^{* * *}$ \\
& $(0.3144)$ & $(0.0504)$ & $(0.5111)$ \\
\hline Observations & 300 & 330 & 330 \\
\hline \hline
\end{tabular}

Linear regression with random effects at the session level.

Average Contribution in SM refers to the average contribution in the strategy method

Average Contribution in One-Shot refers to the average contribution in the one-shot game ${ }^{*} p<0.1,{ }^{* *} p<0.05,{ }^{* * *} p<0.01$ 


\section{INSTRUCTIONS}

These are the instructions for the three parts of the SEQUENTIAL treatment. The instructions for the other treatments were appropriately adjusted and will be available for download from the author's website.

\section{General Instructions}

Welcome to this economic experiment. In the experiment you and other participants will make decisions. Next to the fee of $\mathbf{5} \mathbf{C H F}$ for showing up in time, you can earn money in the experiment. How much you earn depends on your own decisions and the decisions of other participants. At the end of the experiment the show-up fee and the earnings from the different parts will be added up and confidentially paid out to you in cash.

The experiment consists of three parts that are all independent of one another. For each part you will receive specific instructions. These instructions will explain how you make decisions and how your decisions and the decisions of other participants influence your earnings. Therefore, it is important that you read the instructions carefully.

From now on you are not allowed to communicate in any other way than specified in the instructions. Please obey to this rule because otherwise we have to exclude you from the experiment and all earnings you have made will be lost. Please also do not ask questions aloud. If you have a question raise your hand. A member of the experimenter team will come to you and answer your question in private.

You can now start reading the instructions for the first part of the experiment. Other instructions will follow after Part 1 is over. 


\section{Specific instructions - Part 1}

In this part of the experiment, you can earn money with the decisions you make. How much you earn depends on your own decisions, as well as the decisions of other participants. We will not speak of Swiss francs during the experiment, but rather of tokens. All you earnings will first be calculated in tokens. At the end of the experiment the total amount of tokens you earned in this part will be converted to Swiss francs at the following rate:

\section{1 token $=0.6$ Swiss francs}

Earnings will be rounded up to the next integer.

At the beginning of this part of the experiment all participants will be divided into groups of three. You will not get to know the identity of the other group members, neither during nor after the experiment. The other group members will also not get to know your identity.

We now describe how this part of the experiment proceeds. First you will be introduced to the basic decision situation, thereafter you will learn more specifically how the experiment is conducted. You will also be asked some control questions that will help you to understand the decision situation.

The decision situation:

You will be the member of a group of 3 people. Each group member receives an endowment of 20 tokens. You and each other group member has to simultaneously decide on the assignment of his/her 20 tokens. You can put any (integer) share of these 20 tokens into your account A or you can put any (integer) share to account $B$.

The decision you will make is how many tokens you want to assign to account B. The assignment of tokens to your account A will automatically be calculated as:

Your assignment to your account $A=(20$ - tokens you assigned to account $B)$

Your earnings from your account A:

For each token you put into your account $A$, you will earn one token. That is, Your earnings from your account $A=$ tokens assigned to your account $A$ $=(20$ - tokens you assign to account $B)$

For example, if you put 20 tokens into your account A, your earnings from your account A will be 20 tokens. If you put, for example, 6 tokens into your account $A$, your earnings from this account will be the 6 tokens.

No one except you earns tokens from your account A. You do not earn anything from the assignments of the other group members to their account $A$. For example, if you put 10 tokens into your account $A$, and the other group members each put 20 tokens in their respective account $A$, then your earnings from your account $A$ will be 10 tokens.

Your earnings from account B: 
For each token you assign to account B, each group member will profit equally. On the other hand, you will also profit from the other group members' assignments to account $B$, and this regardless of whether you assign tokens to account B. For each group member the earnings from account B will be determined as follows:

\section{Earnings from account $B=0.5 *($ sum of assignments to account $B$ of all group members)}

For example, if you assign 20 tokens to account B and each of the other two members also assign 20 tokens to account $\mathrm{B}$, then the sum of assignments is 60 tokens. This means that you and each of the other two group members earn $0.5 * 60=30$ tokens from account $B$. If, for example, you assign 6 tokens to account $\mathrm{B}$, and one of the other members assigns 2 tokens and the third one 1 tokens to account $\mathrm{B}$, then the sum of assignments is 9 tokens. In this case you and each of the other two group members earn $0.5^{*} 9=4.5$ tokens from account B.

Notice that your decision is to allocate your 20 tokens between your account A and account B. In order to do so, you will be asked how many, out of these 20 tokens, you want to assign to account B. The assignment of tokens to account A will automatically be calculated as:

Your assignment to account $A=(20$ - tokens you assigned to account $B)$

Your total earnings from your account A, account B and the tokens others assign to their respective account A are:

Total earnings $=(20$ - tokens you assigned to account $B)$ $+0.5 *$ ( sum of assignments to account $B$ of all group members)

For example:

1. If the sum of assignments to account B was $(20+20+20)=60$, then your total earnings $=(20-20)+(0.5 * 60)=30$.

2. If the sum of assignments to account $B$ was $(6+2+1)=9$ and you assigned 6 to account $B$, then your total earnings $=(20-6)+(0.5 * 9)=18.5$

3. If the sum of assignments to account B was $(2+9+19)=30$ and you assigned 2 to account $B$, then your total earnings $=(20-2)+(0.5 * 30)=33$. 


\section{Control questions - decision situation:}

Please answer the following control questions. These questions are arbitrary examples of what could happen in the experiment. They will help you to gain an understanding of the calculation of your earnings. Your earnings vary with your own decision and with the decisions of the other group members.

Please answer all the questions and write down your calculations.

1. Each group member is endowed with 20 tokens. Assume that none of the group members (including you) assigns anything to account B.

What will your total earnings be?

What will the total earnings of each of the other group members be?

2. Each group member is endowed with 20 tokens. You assign 20 token to account B. Each of the other 2 group members each assigns 0 token to account $\mathrm{B}$.

What will your total earnings be?

What will the total earnings of each of the other group members be?

3. Each group member is endowed with 20 tokens. The other 2 group members assign a total of 30 tokens to account B.

a) What will your total earnings be, if you assign 0 token to account B?

Your total earnings

b) What will your total earnings be, if you assign 8 tokens to account B?

Your total earnings

c) What will your total earnings be, if you assign 15 tokens to account B?

Your total earnings

4. Each group member is endowed with 20 tokens. Assume that you assign 8 tokens to account B.

a) What will your total earnings be, if the other group members assign, in total, 7 tokens to account B? Your total earnings

b) What will your total earnings be, if the other group members assign, in total, 12 tokens to account B? Your total earnings

c) What will your total earnings be, if the other group members assign, in total, 22 tokens to account B?

Your total earnings

ONCE YOU ARE DONE FILLING THE CONTROL QUESTIONS, PLEASE RAISE YOUR HAND AND ONE OF THE EXPERIMENTER WILL COME TO CHECK YOUR ANSWERS. 


\section{The experiment:}

In this part of the experiment you will be confronted with the described decision situation only once. You can put any integer share of your 20 tokens into your account A or into account B. Each participant has to make two types of decisions in this part of the experiment, which we will refer to below as the "unconditional assignment decision" and the "assignment table".

1. Unconditional assignment decision: Here you decide how many of the 20 tokens you want to put in account B. When making your decision you may want to consult the summary of the decision situation you received with these instructions.

You will have to indicate your assignment decision on a screen as shown below:

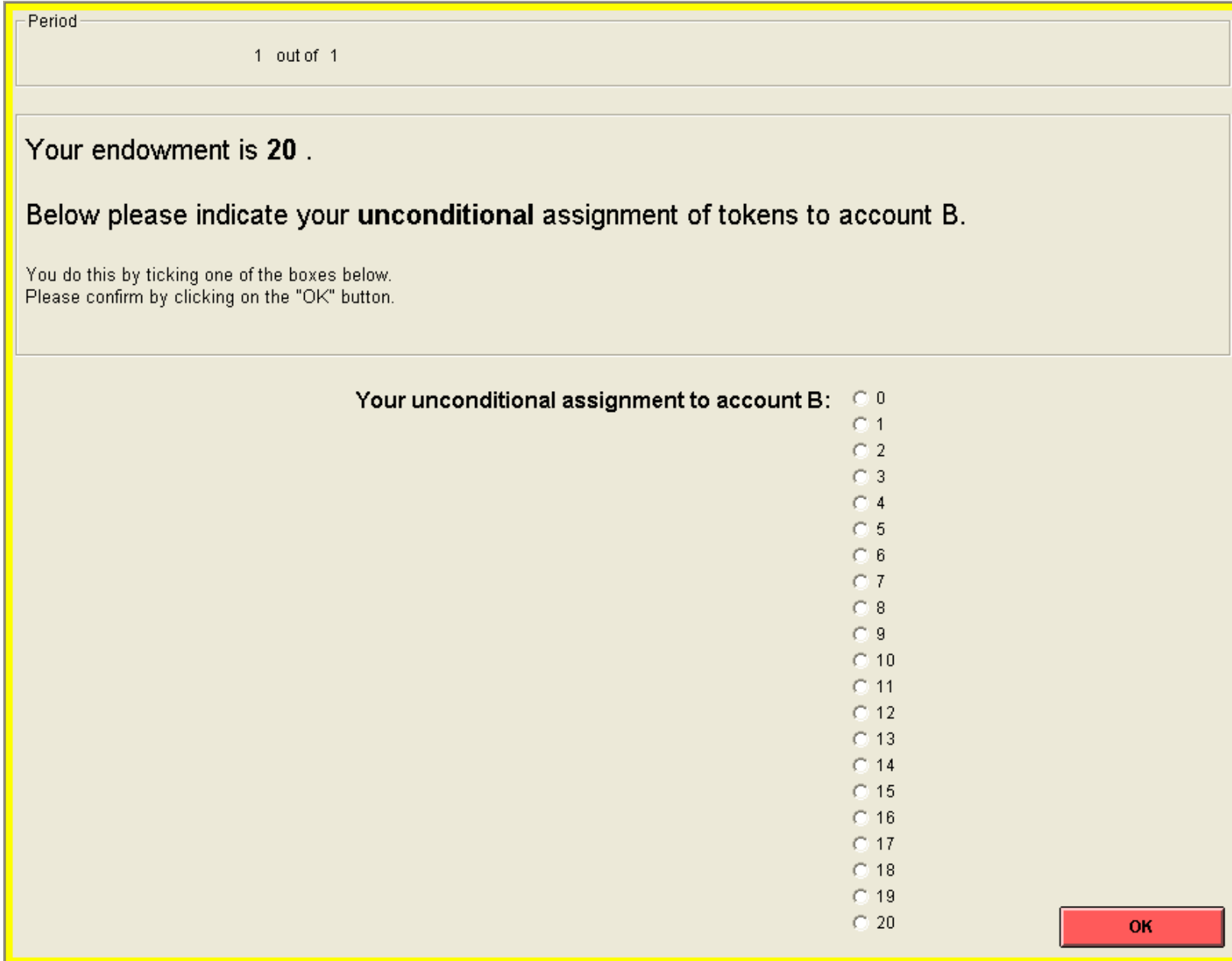

2. Assignment table decision: Here you will face 21 successive screens in which you will have to indicate how many tokens you want to assign to account $B$, for each possible average number of tokens the other group members put in account $\mathbf{B}$ (rounded to the next integer). Each of the 21 screen will refer to an average number of tokens the other group members put in account $\mathbf{B}$ (there are 21 such possible rounded average: $0,1,2, \ldots, 20)$. What this means will be immediately clear to you if you take a look at the computer screens shown below.

This screen is one out of the 21 screen you will see. The numbers to the left of the empty box is the possible (rounded) average assignments of the other group members to account $\mathbf{B}$. You simply have to 
insert in the box how many tokens you will assign to account B, conditional on the indicated average number of tokens assigned by the other group members. You have to make an entry in the box for each of the 21 screen. For example, you will have to indicate how much you assign to account B if the others assign an average of 0 token to account $\mathrm{B}$, how much you assign to account $\mathrm{B}$ if the others assign an average of 1, 2, or 3 tokens, etc. You can insert any integer number from 0 to 20, in each box. When making your decisions you may want to consult the summary of the decision situation you received with these instructions. When you have made your entry in the box, please click "OK" and the next screen will appear until you have made your 21 "conditional” assignment decisions.

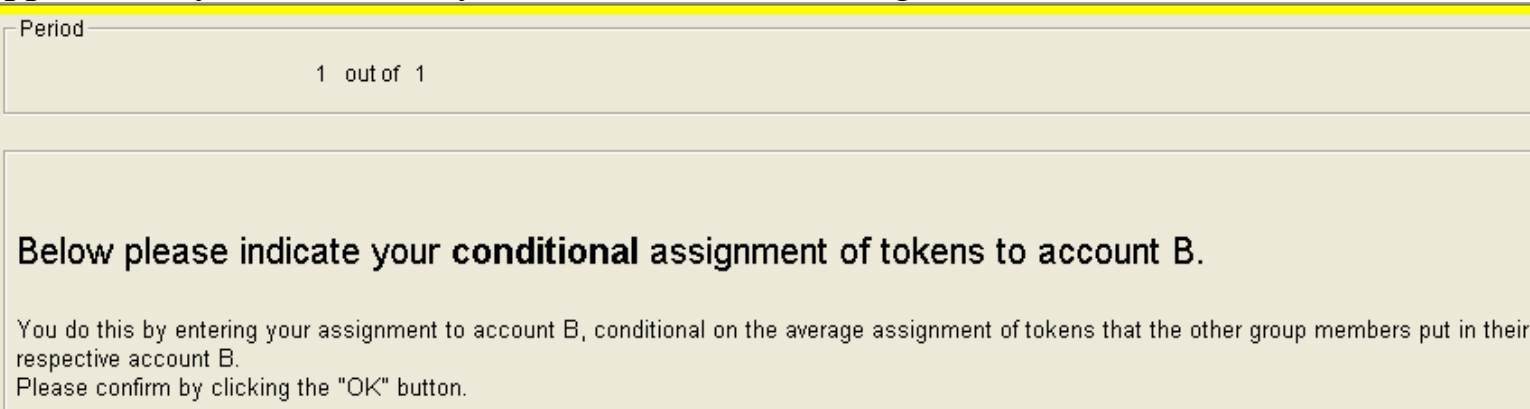

11

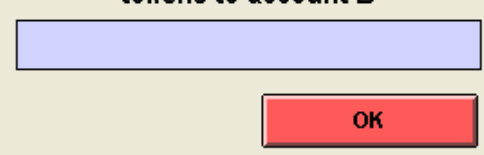

Once you have filled an assignment in the box. The next screen will appear as shown below: 


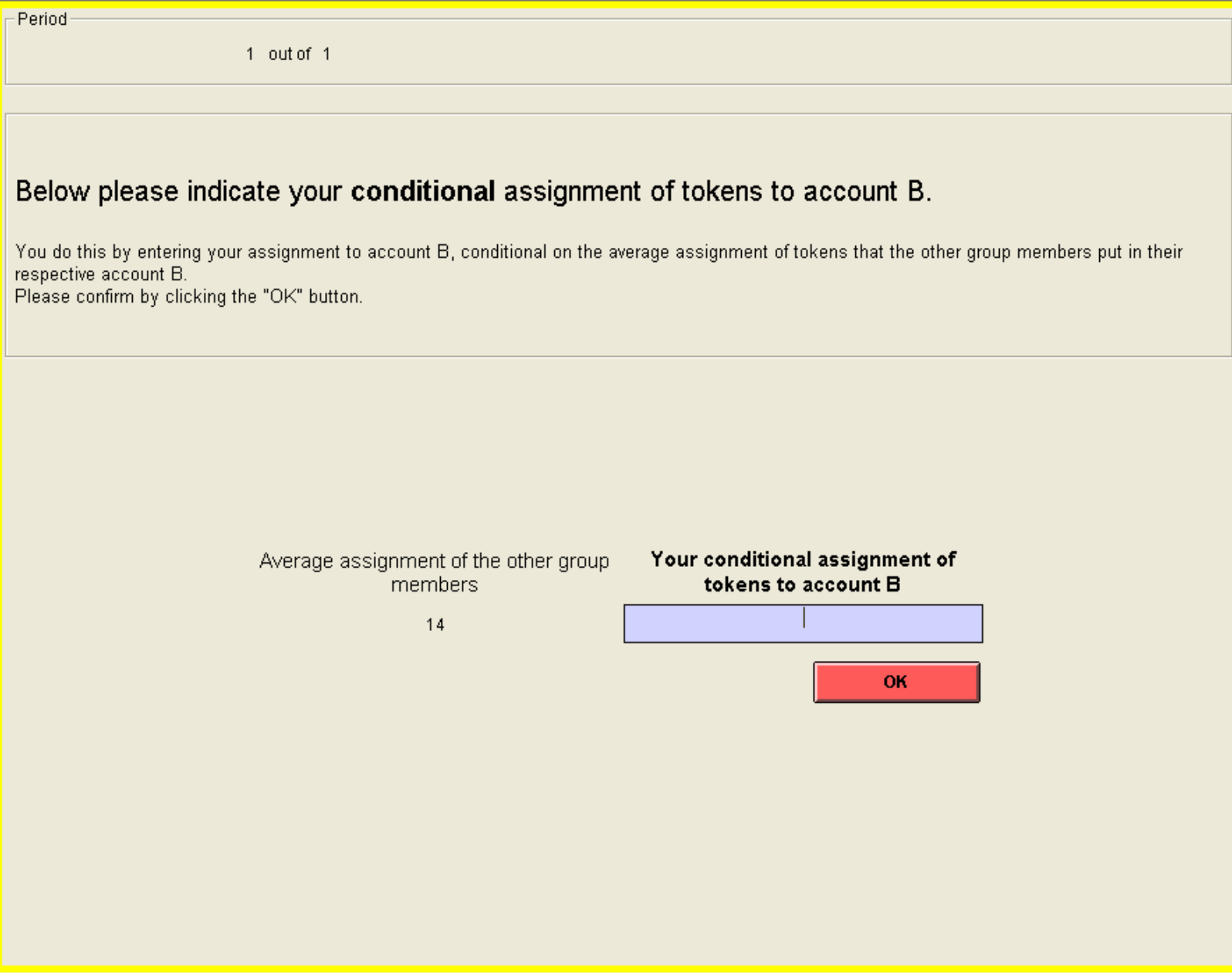

You will see in total 21 such screens, each corresponding to a possible average assignment of the other group members to account B. You will never see the same average assignment twice. That is, each of the 21 screens will refer to a different average assignment of the other group members to account B. For the sake of brevity, we have shown to you only two of the 21 successive screens you will see.

After you have made your unconditional assignment decision and your assignment table decision (21 successive screens) you have to estimate the actual average unconditional assignment to account $B$ (rounded to an integer) of the other two group members. You will be paid for the accuracy of your estimate:

- If your estimate is exactly right (that is, if your estimate exactly matches the rounded actual average assignment of the other group members), you will receive $\mathbf{3}$ points extra to your other earnings from the experiment.

- If your estimate deviates by 1 point from the actual result, you will receive 2 points extra.

- If your estimate deviates by $\mathbf{2}$ points from the actual result, you will receive 1 point extra

- If your estimate deviates by $\mathbf{3}$ or more points from the actual result, you will receive no points extra.

You will make your estimation decision on a screen as shown below. 


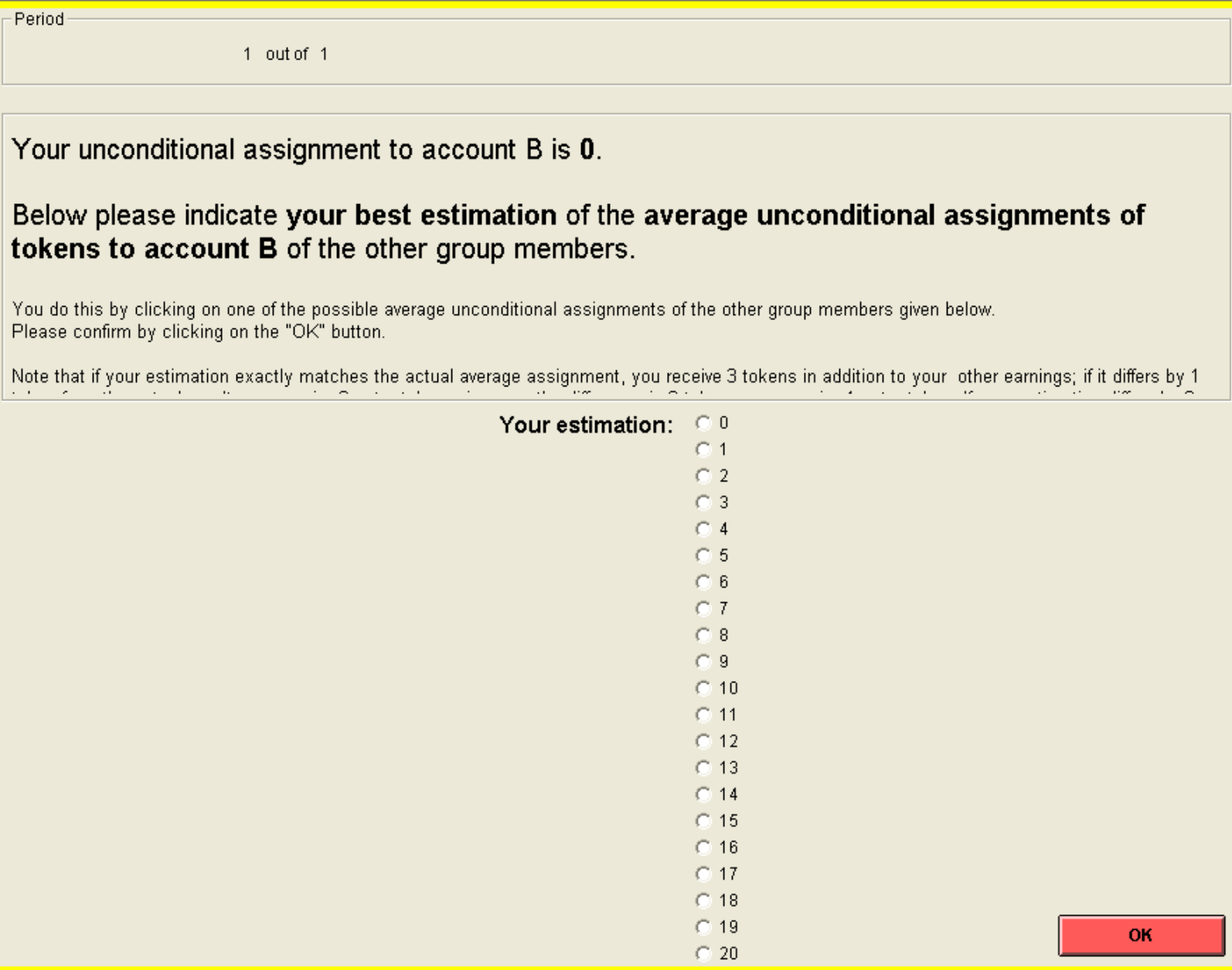

After all participants of the experiment have made their unconditional assignment decision and their assignment table decision, a random mechanism will select a group member from every group. For this randomly selected group member only the assignment table will be the payoff-relevant decision. For the other two group members only the unconditional assignment will be the payoff-relevant decision. Obviously, when you make your unconditional assignment decision and your assignment table decisions you do not know whether the random mechanism will select you or not. Therefore, you will have to think carefully about both types of decisions because both can become payoff relevant for you. Two examples will make this clear.

EXAMPLE 1: Assume that the random mechanism selects you. This implies that your relevant decision will be your assignment table. The unconditional assignment is the relevant decision for the other two group members. Assume that they made unconditional assignments of 1 and 3 tokens. The average assignment of tokens of these two group members, therefore, is 2 tokens. If you indicated in your assignment table that you would assign 1 token to account B if the others put 2 tokens on average in account $B$, then your total earnings would be $(20-1)+0.5 * 5=21.5$. The other two group members earn the 2.5 tokens plus their respective earnings from their own account A. If, instead, you indicated in your assignment table that you would assign 16 tokens if the others assign two tokens on average, then the total assignment of the group to account $B$ is given by $1+3+16=20$ tokens. All group members therefore earn $0.5 \times 20=10$ tokens from the account B. Your total earnings would be $(20-16)+10=14$ tokens. The other two group members earn the 14 tokens plus their respective earnings from their own account $\mathrm{A}$. 
EXAMPLE 2: Assume that the random mechanism did not select you, implying that the unconditional assignment of tokens to your account $B$ is taken as the payoff-relevant decision for you and one other group member. Assume that your unconditional assignment is 16 tokens and the other group member who was also not chosen put 20 tokens in account B. The average unconditional assignment of you and that of the other group member, therefore, is $(20+16) / 2=18$ tokens. If the group member who was selected by the random mechanism indicates in the assignment table to assign 1 token to account $\mathrm{B}$ if the other two group members put on average 18 tokens in account $\mathrm{B}$, then the total contribution of the group to the project is given by $16+20+1=37$ tokens. All group members will therefore earn $0.5 \times 37=18.5$ tokens from account B. Your total earnings would be $(20-16)+18.5=22.5$ tokens. The other two group members earn the 18.5 tokens plus their respective earnings from their own account A. If, instead, the randomly selected group member indicates in the assignment table to assign 18 tokens to account $B$ if the others contribute on average 18 tokens to account $B$, then the total assignment of the group to account $B$ is given by $16+20+18=54$ tokens. All group members will therefore earn $0.5 \times 54=27$ tokens from account B. Your total earnings would be $(20-16)+27=31$ tokens. The other two group members earn the 27 tokens plus their respective earnings from their own account A. tokens.

The random selection of one of the group members will be implemented as follows. Each group member is assigned an integer number between 1 and 3. Please recall, that one participant, namely the one with the cubicle number 1, was randomly chosen at the very beginning of the experiment. After all participants have made all their decisions, this participant will throw a 6-sided die. The result of this throw determines for which member number in each group the contribution table decisions are payoffrelevant. The member with number 1 is selected if the die gives 1 or 4 ; the member with number 2 is selected if the die gives 2 or 5 ; the member with number 3 is selected if the die gives 3 or 6 .

If the participant at cubicle number 1 throws the member number that was assigned to you, then your assignment table will be payoff-relevant for you and the unconditional assignment will be the payoffrelevant decision for the other group members. Otherwise, your unconditional assignment is the payoffrelevant decision for you.

This is the end of the instructions. If you have a question please raise your hand. 


\section{Specific instructions - Part 2}

In this part of the experiment you can earn money with the decisions you make. How much you earn depends on your own decisions and the decisions of other participants. We will not speak of Swiss Francs during the experiment, but rather of tokens. All you earnings will first be calculated in tokens. At the end of the experiment the total amount of tokens you earned in this part will be converted to Swiss Francs at the following rate:

$$
1 \text { token }=0.6 \mathrm{CHF}
$$

At the beginning of this part of the experiment all participants will be divided in groups of three. You will not get to know the identity of the other group members, neither during nor after the experiment. The other group members will also not get to know your identity.

The decision situation in this part of the experiment is the same as in part 1 . For your convenience we briefly repeat the description of the decision situation.

The decision situation:

You will be the member of a group of $\mathbf{3}$ people. Each group member receives an endowment of 20 tokens. You and each other group member has to simultaneously decide on the assignment of his/her 20 tokens. You can put any (integer) share of these 20 tokens into your account A or you can put any (integer) share to account $\mathbf{B}$.

The decision you will make is how many tokens you want to assign to account B. The assignment of tokens to your account A will automatically be calculated as:

Your assignment to your account $A=(20$ - tokens you assigned to account $B)$

Your earnings from your account A:

For each token you put into your account $\mathrm{A}$, you will earn one token. That is,

Your earnings from your account $A=$ tokens assigned to your account $A$

$$
=(20-\text { tokens you assign to account } B)
$$

Recall that no one except you earns tokens from your account A. You do not earn anything from the assignments of the other group members to their account $A$

\section{Your earnings from account B:}

For each token you assign to account B, each group member will profit equally. On the other hand, you will also profit from the other group members' assignments to account $B$, and this regardless of whether you assign tokens to account B. For each group member the earnings from account B will be determined as follows:

\section{Earnings from account $B=0.5 *($ sum of assignments to account $B$ of all group members)}

Your total earnings from your account A, account B and the tokens others assign to their respective account A are:

Total earnings $=(20$ - tokens you assigned to account $B)$ 


\section{$+0.5 *$ ( sum of assignments to account B of all group members)}

In this part of the experiment you will be engaged in the decision situation for $\mathbf{1}$ period.

You and the other group members have to make an assignment decision and an estimation of the actual average assignments of the other 2 group members. When you make your decisions you do not know the decisions of the other group members nor do the other group members know your decisions.

You will make your assignment decision on a computer screen as shown on the next page:

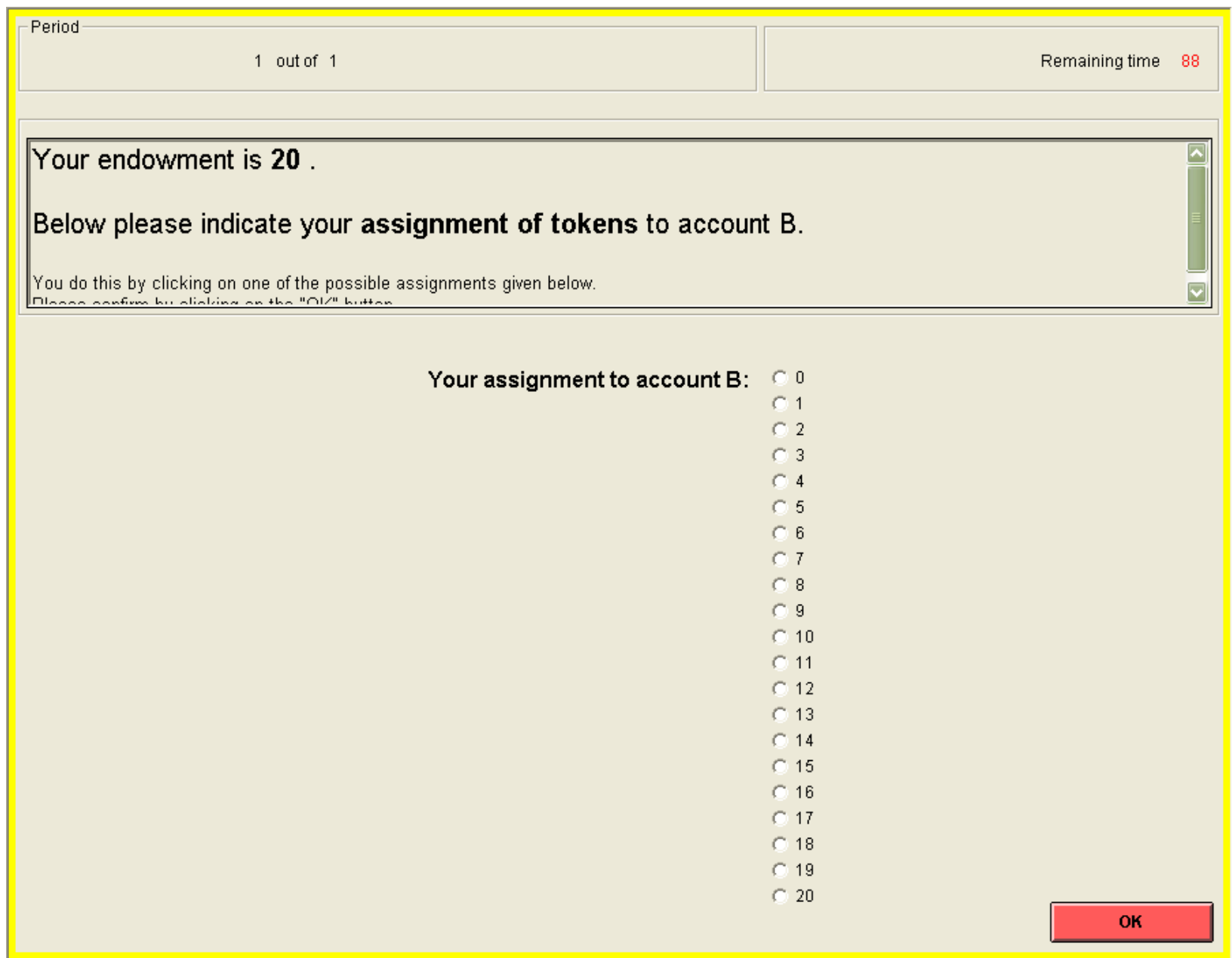

On this screen, you have to decide on your assignment of tokens to account $\mathbf{B}$. That is, you have to decide how many of the 20 tokens you want to put in account $\mathrm{B}$, and how many tokens you want to put into your account $\mathrm{A}$. When making your decisions you may want to consult the summary of the decision situation you received with these instructions.

After you have made and confirmed your decision you have to indicate your estimation of the actual average assignment to account $B$ of the other 2 group members.

You will indicate your estimation on a computer screen as shown on the next page: 


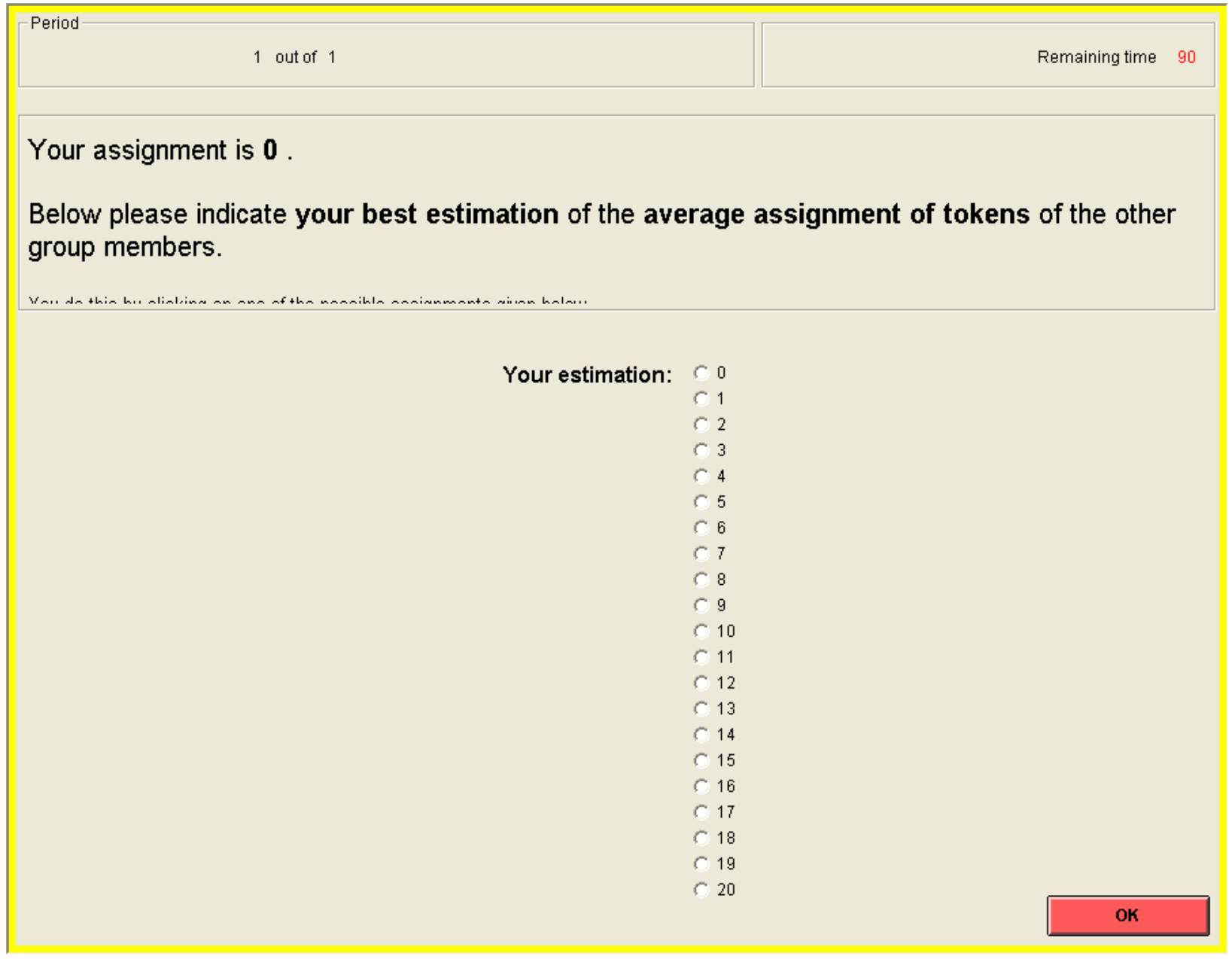

As in part 1 of the experiment you can earn money with the accuracy of your estimate.

3. If your estimate is exactly right (that is, if your estimate exactly matches the rounded actual average assignment to account B of the other group members), you will receive $\mathbf{3}$ tokens extra to your other earnings from the experiment.

4. If your estimate deviates by $\mathbf{1}$ token from the actual result, you will receive $\mathbf{2}$ tokens extra.

5. If your estimate deviates by $\mathbf{2}$ tokens from the actual result, you will receive $\mathbf{1}$ token extra

6. If your estimate deviates by 3 or more tokens from the correct result, you will receive no tokens extra.

At the end of the period, you will know your earnings in this part of the experiment and you will also receive information about the assignment decisions made by the others. As indicated in part 1 of the experiment, you will next be told the results of part 1 . After that, the third part of the experiment will start.

This is the end of the instructions. If you have a question please raise your hand. 


\section{Specific instructions - Part 3}

In this part of the experiment you can earn money with the decisions you make. How much you earn depends on your own decisions and the decisions of other participants. We will not speak of Swiss Francs during the experiment, but rather of tokens. All you earnings will first be calculated in tokens. At the end of the experiment the total amount of tokens you earned in this part will be converted to Swiss Francs at the following rate:

$$
1 \text { token }=0.06 \mathrm{CHF}
$$

At the beginning of this part of the experiment all participants will be divided in groups of three. You will not get to know the identity of the other group members, neither during nor after the experiment. The other group members will also not get to know your identity.

The decision situation in this part of the experiment is the same as in Part 2. In this part of the experiment you will be engaged in the decision situation for 10 successive periods. In each period you and the other two group members will be randomly rematched. Thus, in no period will your group consist of the same three people.

For your convenience we briefly repeat the description of the decision situation.

The decision situation:

You will be the member of a group of 3 people. Each group member receives an endowment of 20 tokens. You and each other group member has to simultaneously decide on the assignment of his/her 20 tokens. You can put any (integer) share of these 20 tokens into your account A or you can put any (integer) share to account $\mathbf{B}$.

The decision you will make is how many tokens you want to assign to account B. The assignment of tokens to your account A will automatically be calculated as:

Your assignment to your account $A=(20$ - tokens you assigned to account $B)$

Your earnings from your account A:

For each token you put into your account $\mathbf{A}$, you will earn one token. That is,

Your earnings from your account $A=$ tokens assigned to your account $A$ $=(20$ - tokens you assign to account $B)$

Recall that no one except you earns tokens from your account A. You do not earn anything from the assignments of the other group members to their account $A$

Your earnings from account B:

For each token you assign to account $B$, each group member will profit equally. On the other hand, you will also profit from the other group members' assignments to account $B$, and this regardless of whether you assign tokens to account $B$. For each group member the earnings from account B will be determined as follows:

Earnings from account B = $0.5 *($ sum of assignments to account $B$ of all group members)

Your total earnings from your account A, account B and the tokens others assign to their respective 
account A are:

Total earnings $=(20$ - tokens you assigned to account $B)$ $+0.5 *$ ( sum of assignments to account $B$ of all group members)

As said above, in this part of the experiment you will be engaged in the decision situation for $\underline{\mathbf{1 0}}$ successive periods. In each period you and the other two group members will be randomly rematched. Thus, in no period will your group consist of the same three people.

In each period you and the other group members have to make an assignment decision and an estimation of the actual average assignments of the other 2 group members. When you make your decisions you do not know the decisions of the other group members nor do the other group members know your decisions. At the end of each period you will be informed about the total assignments in your group in that period as well as your earnings in that period.

In each period, you will make your assignment decision on a computer screen as shown below:

\begin{tabular}{|c|c|c|}
\hline \multicolumn{3}{|l|}{ Period } \\
\hline 1 out of 2 & Remaining time 7 & 79 \\
\hline \multicolumn{3}{|c|}{ 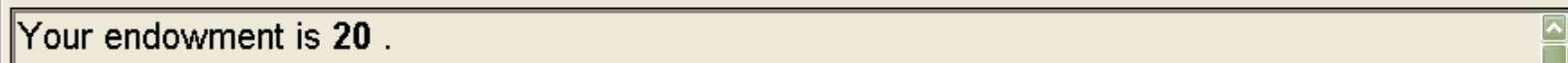 } \\
\hline \multicolumn{3}{|c|}{ Below please indicate your assignment of tokens to account $B$ in this period. } \\
\hline You do this by clicking on one of the possible assignments given below. & & 要 \\
\hline
\end{tabular}

Your assignment to account $B: \curvearrowright 0$

$\ulcorner 1$

C 3

C 4

C 5

r 6

$\ulcorner 7$

C 8

r 9

C 10

ऽ 11

$\ulcorner 12$

C 13

C 14

C 15

C 16

ऽ 17

C 18

C 19

C 20

On this screen, you have to decide on your assignment of tokens to account B. That is, you have to decide how many of the 20 tokens you want to put in account $\mathrm{B}$, and how many tokens you want to put into your account A. When making your decisions you may want to consult the summary of the decision situation you received with these instructions. 
In each period, after you have made and confirmed your decision you have to indicate your estimation of the actual average assignment to account $B$ of the other 2 group members.

In each period, you will indicate your estimation on a computer screen as shown on the next page:



As in part 1 and 2 of the experiment you can earn money with the accuracy of your estimate.

7. If your estimate is exactly right (that is, if your estimate exactly matches the rounded actual average assignment to account $\mathrm{B}$ of the other group members), you will receive $\mathbf{3}$ tokens extra to your other earnings from the experiment.

8. If your estimate deviates by $\mathbf{1}$ token from the actual result, you will receive $\mathbf{2}$ tokens extra.

9. If your estimate deviates by $\mathbf{2}$ tokens from the actual result, you will receive $\mathbf{1}$ token extra

10. If your estimate deviates by $\mathbf{3}$ or more tokens from the correct result, you will receive no tokens extra.

After the 10 periods of this part are over you will be asked to fill in a short questionnaire. Thereafter, the whole experiment is over and you will be confidentially paid out your total earnings in the experiment in cash.

This is the end of the instructions. If you have a question please raise your hand.

\section{Specific instructions - Part 3}

In this part of the experiment you can earn money with the decisions you make. How much you earn 
depends on your own decisions and the decisions of other participants. We will not speak of Swiss Francs during the experiment, but rather of tokens. All you earnings will first be calculated in tokens. At the end of the experiment the total amount of tokens you earned in this part will be converted to Swiss Francs at the following rate:

$$
1 \text { token }=0.06 \mathrm{CHF}
$$

At the beginning of this part of the experiment all participants will be divided in groups of three. You will not get to know the identity of the other group members, neither during nor after the experiment. The other group members will also not get to know your identity.

The decision situation in this part of the experiment is the same as in Part 2. In this part of the experiment you will be engaged in the decision situation for 10 successive periods. In each period you and the other two group members will be randomly rematched. Thus, in no period will your group consist of the same three people.

For your convenience we briefly repeat the description of the decision situation.

The decision situation:

You will be the member of a group of 3 people. Each group member receives an endowment of 20 tokens. You and each other group member has to simultaneously decide on the assignment of his/her 20 tokens. You can put any (integer) share of these 20 tokens into your account $\mathbf{A}$ or you can put any (integer) share to account $\mathbf{B}$.

The decision you will make is how many tokens you want to assign to account B. The assignment of tokens to your account A will automatically be calculated as:

Your assignment to your account $A=(20$ - tokens you assigned to account $B)$

Your earnings from your account A:

For each token you put into your account $\mathbf{A}$, you will earn one token. That is,

Your earnings from your account $A=$ tokens assigned to your account $A$ $=(20$ - tokens you assign to account $B)$

Recall that no one except you earns tokens from your account A. You do not earn anything from the assignments of the other group members to their account $\mathrm{A}$

\section{Your earnings from account B:}

For each token you assign to account $B$, each group member will profit equally. On the other hand, you will also profit from the other group members' assignments to account $B$, and this regardless of whether you assign tokens to account $B$. For each group member the earnings from account $B$ will be determined as follows:

Earnings from account B = $0.5 *($ sum of assignments to account $B$ of all group members)

Your total earnings from your account A, account B and the tokens others assign to their respective account A are:

Total earnings $=(20$ - tokens you assigned to account $B)$ 


\section{$+0.5 *$ ( sum of assignments to account B of all group members)}

As said above, in this part of the experiment you will be engaged in the decision situation for $\underline{\mathbf{1 0}}$ successive periods. In each period you and the other two group members will be randomly rematched. Thus, in no period will your group consist of the same three people.

In each period you and the other group members have to make an assignment decision and an estimation of the actual average assignments of the other 2 group members. When you make your decisions you do not know the decisions of the other group members nor do the other group members know your decisions. At the end of each period you will be informed about the total assignments in your group in that period as well as your earnings in that period.

In each period, you will make your assignment decision on a computer screen as shown below:

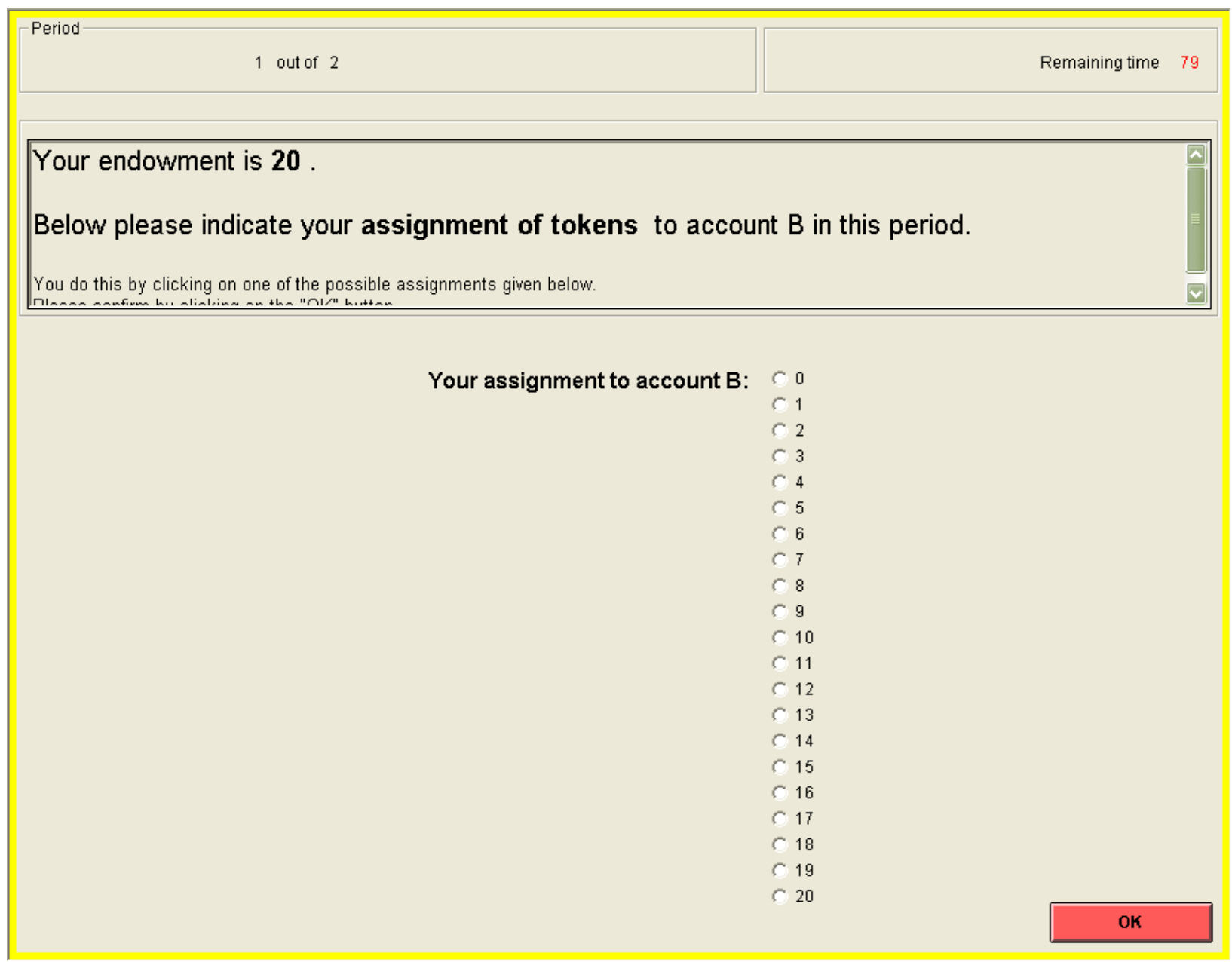

On this screen, you have to decide on your assignment of tokens to account $B$. That is, you have to decide how many of the 20 tokens you want to put in account $\mathrm{B}$, and how many tokens you want to put into your account $\mathrm{A}$. When making your decisions you may want to consult the summary of the decision situation you received with these instructions.

In each period, after you have made and confirmed your decision you have to indicate your estimation of the actual average assignment to account $B$ of the other 2 group members. 
In each period, you will indicate your estimation on a computer screen as shown on the next page:

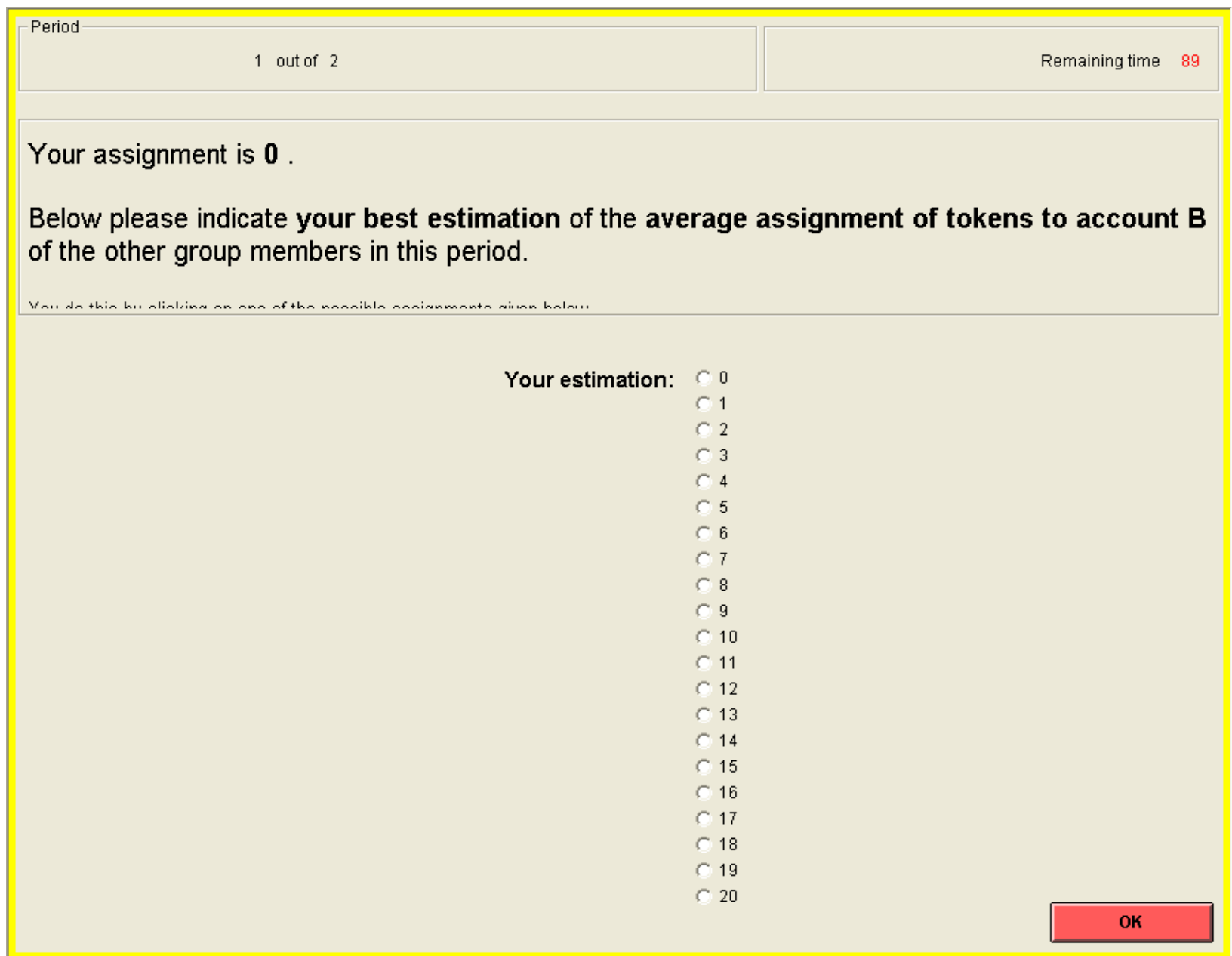

As in part 1 and 2 of the experiment you can earn money with the accuracy of your estimate.

11. If your estimate is exactly right (that is, if your estimate exactly matches the rounded actual average assignment to account $\mathrm{B}$ of the other group members), you will receive $\mathbf{3}$ tokens extra to your other earnings from the experiment.

12. If your estimate deviates by $\mathbf{1}$ token from the actual result, you will receive $\mathbf{2}$ tokens extra.

13. If your estimate deviates by $\mathbf{2}$ tokens from the actual result, you will receive $\mathbf{1}$ token extra

14. If your estimate deviates by $\mathbf{3}$ or more tokens from the correct result, you will receive no tokens extra.

After the 10 periods of this part are over you will be asked to fill in a short questionnaire. Thereafter, the whole experiment is over and you will be confidentially paid out your total earnings in the experiment in cash.

This is the end of the instructions. If you have a question please raise your hand. 